Published in final edited form as:

Cancer Lett. 2015 December 1; 369(1): 229-241. doi:10.1016/j.canlet.2015.08.021.

\title{
The Vascular Disrupting Activity of OXi8006 in Endothelial Cells and Its Phosphate Prodrug OXi8007 in Breast Tumor Xenografts
}

\author{
Tracy E. Strecker ${ }^{a,{ }^{*}}$, Samuel O. Odutolab, ${ }^{\text {, }}$, Ramona Lopez ${ }^{c}$, Morgan S. Coopera ${ }^{a}$ Justin K. \\ Tidmore $^{\mathrm{a}}$, Amanda K. Charlton-Sevcik ${ }^{\mathrm{a}}$, Li Lic, Matthew T. MacDonough ${ }^{\mathrm{a}}$, Mallinath B. \\ Hadimani $^{\mathrm{a}}$, Anjan Ghatak ${ }^{\mathrm{a},}$, Li Liu $^{\mathrm{c}}$, David J. Chaplin ${ }^{\mathrm{d}}$, Ralph P. Mason ${ }^{\mathrm{c}}$, Kevin G. \\ Pinney ${ }^{a, b}$, and Mary Lynn Trawick ${ }^{a, b}$ \\ aDepartment of Chemistry and Biochemistry, Baylor University, Waco, TX 76798-7348 \\ bInstitute of Biomedical Studies, Baylor University, Waco, TX 76798-7224 \\ 'Department of Radiology, University of Texas Southwestern Medical Center, Dallas, TX \\ 75390-9058
}

dOXiGENE Inc., South San Francisco, CA 94080

\begin{abstract}
This study describes the vascular disrupting ability and the mechanism of action of the indolebased tubulin-binding compound, OXi8006, and its water-soluble phosphate prodrug OXi8007. Treatment of rapidly proliferating human umbilical vein endothelial cells (HUVECs), used as a model for the tumor vasculature, with OXi8006 or OXi8007 caused potent microtubule disruption followed by extensive reorganization of the cytoskeletal network. The mechanism of action involved an increase in focal adhesion formation associated with an increase in phosphorylation of both non-muscle myosin light chain and focal adhesion kinase. These effects were dramatically diminished by an inhibitor of RhoA kinase, a downstream effector of RhoA. Cell cycle blockade at G2/M and cytotoxicity towards rapidly proliferating HUVECs were also observed. Capillary-like networks of HUVECs were disrupted by the action of both OXi8006 and OXi8007. The prodrug OXi8007 exhibited potent and rapid dose-dependent antivascular activity assessed by dynamic bioluminescence imaging (BLI) in an MDA-MB-231-luc breast cancer xenograft mouse model. By 6 hours post treatment, over $93 \%$ of the BLI signal was abolished with only a slight recovery at 24 hours. These findings were confirmed by histology. The results from this study demonstrate that OXi8007 is a potent vascular disrupting agent acting through an anti-microtubule mechanism involving RhoA.
\end{abstract}

\footnotetext{
Corresponding Author: Mary Lynn Trawick, Ph.D., Department of Chemistry and Biochemistry, Baylor University, One Bear Place 97348, Waco, TX, 76798-7348, (p) 254-710-6857, (f) 254-710-4272, Mary_Lynn_Trawick@baylor.edu.

These authors contributed equally to this work.

$\dagger$ Dr. Anjan Ghatak deceased July 22, 2003.

Publisher's Disclaimer: This is a PDF file of an unedited manuscript that has been accepted for publication. As a service to our customers we are providing this early version of the manuscript. The manuscript will undergo copyediting, typesetting, and review of the resulting proof before it is published in its final citable form. Please note that during the production process errors may be discovered which could affect the content, and all legal disclaimers that apply to the journal pertain.
} 


\section{Keywords}

vascular disrupting agent (VDA); microtubules; focal adhesion kinase (FAK); bioluminescence imaging (BLI); breast cancer

\section{Introduction}

Tumors require an expanding vasculature in order to grow and metastasize. The immature, chaotic, rapidly growing, activated tumor vascular endothelium is distinct from the largely quiescent, remodeled, and mature normal endothelium. These differences, along with the observation that a limited number of blood vessels supply a large number of cancer cells in the tumor, present the tumor vasculature as a selective target for cancer therapy [1-3]. Vascular disrupting agents (VDAs) [4-6] are a promising class of anticancer agents that act on the preexisting tumor vasculature and are distinct from angiogenesis inhibiting agents such as bevacizumab (Avastin ${ }^{\mathrm{TM}}$ ) that inhibit the growth of new blood vessels but have limited effects on large tumors $[7,8]$. The tubulin-microtubule system is an important anticancer target [9] and the mechanism of tubulin-binding, small-molecule VDAs is potentially two-fold. The major effect is the rapid and pronounced shutdown of blood flow to solid tumors, depriving cancer cells of necessary oxygen and nutrients and resulting in extensive tumor necrosis, while leaving blood flow to normal tissues intact $[3-5,10]$. The secondary effect results from direct antimitotic activity against tumor cells. Treatment with combretastatin A-4 (CA4), a VDA that has advanced to human clinical trials, has been reported to inhibit tumor cell invasion, migration and metastasis [11]. Despite the encouraging positive pre-clinical studies and human clinical trial results of members of this class of anticancer agents, no VDA has yet been approved by the FDA [12-16]. Clearly this provides an opportunity to expand the compound landscape available for therapy.

OXi8006 is one of the first indole-based, colchicine-site binding, inhibitors of tubulin assembly into microtubules. Our previous studies demonstrated that OXi8006 was a potent inhibitor of tubulin polymerization $\left(\mathrm{IC}_{50}=1.1 \mu \mathrm{M}\right)$ and competed with radiolabeled colchicine at the colchicine binding site of tubulin [17]. We also found OXi8006 to be cytotoxic against three evaluated human cancer cell lines, NCI-H460, DU-145 and SK$\mathrm{OV}-3$, with an average $\mathrm{GI}_{50}$ of $25.7 \mathrm{nM}$ [17]. The core indole molecular structure is now widely represented as a key component of a variety of inhibitors of tubulin assembly [18], but OXi8006 remains one of the most active compounds in this group with respect to tubulin binding and cytotoxicity. The very limited solubility of OXi8006 in aqueous solutions led to the synthesis of its water-soluble disodium phosphate prodrug OXi8007[17]. In preliminary studies, Color-Doppler ultrasound was used to image pronounced selective interference with the tumor vasculature upon OXi8007 treatment using a SCID mouse model bearing a human prostate tumor xenograft (PC-3) [17] indicating vascular disrupting properties. In separate studies, only a minimal effect was observed in a mouse model of the Ewing's sarcoma family (TC-32) of tumors [19]. In this study, we confirm the VDA properties and provide information on the biochemical and biological mechanism of action of OXi8006 and its phosphate prodrug OXi8007 (Fig. 1) [17, 20, 21]. 
In order to elucidate the mechanism of OXi8006 action, we assessed the cytoskeletal effects in rapidly proliferating endothelial cells which were used as a model for the tumor vasculature [22-24]. We observed that OXi8006 rapidly initiated loss of microtubules, which elicited other cytoskeletal reorganizations and pronounced morphology changes. These effects suggested that RhoA and the RhoA kinase pathway are involved in the cell signaling events leading to cell rounding and detachment [5]. Since focal adhesions are also significantly involved in regulating cell contraction and movement, we examined the activation status of focal adhesion kinase. The ability of OXi8006 to induce G2/M arrest, act as a cytotoxic agent against HUVECs, and to disrupt a preformed tubular network of endothelial cells, all hallmarks of VDA action, was also investigated. We demonstrate conclusively that OXi8007 is able to effectively disrupt the tumor vasculature in a human breast cancer xenograft model in SCID mice at a dose that was well tolerated (OXi8007 is converted to OXi8006 by the abundant non-specific phosphatase enzymes present in vivo).

\section{Materials and Methods}

\subsection{Compounds}

CA4 and CA4P were obtained from OXiGENE Inc. (South San Francisco, CA), doxorubicin was obtained from Sigma-Aldrich, and OXi8006 and OXi8007 were synthesized as previously described $[17,21]$.

\subsection{Cell Culture}

HUVECs (Invitrogen) were grown on collagen-I coated flasks (CELLCOAT®) in M200 medium (Invitrogen) supplemented with $1 \%$ gentamycin sulfate, $1 \%$ amphotericin $\mathrm{B}$, and high growth factor supplement kit (Endothelial Cell Growth Kit-VEGF (ATCC)). HUVECs were not used beyond passage 5. MDA-MB-231 cells (ATCC) were cultured in DMEM supplemented with $10 \%$ fetal bovine serum (Gibco One Shot ${ }^{\circledR}$ ) and $1 \%$ gentamycin sulfate, and passaged according to ATCC recommendations. Cells were maintained at $37{ }^{\circ} \mathrm{C}$ in a humidified atmosphere of $5 \% \mathrm{CO}_{2}$, for use in these experiments.

\subsection{Fluorescence Imaging of Endothelial Cells}

Actively proliferating HUVECs were cultured on glass coverslips coated with $1 \%$ gelatin. Cells were plated at 10,000 cells/coverslip in 6-well culture plates (Corning) using high growth factor supplemented medium and allowed to incubate at $37^{\circ} \mathrm{C}$ for 48 hours (approximately $40 \%$ confluence) before being treated with compounds. Time dependent effects of compounds on HUVECs were measured using $10 \mathrm{nM}$ compound for specific periods of time $(5,10,15,30,60$ and 120 minutes). Cells were also treated with increasing concentrations of compounds ( $2 \mathrm{nM}-100 \mathrm{nM})$ for $2 \mathrm{~h}$ to observe dose dependent effects. To demonstrate the response to higher compound concentrations, cells were exposed to $1 \mu \mathrm{M}$ of compound for $1 \mathrm{~h}$. The effects of a Rho kinase inhibitor Y-27632 (Sigma Aldrich) were determined by pretreatment of cells ( $30 \mathrm{~min}$ ) with $10 \mu \mathrm{M}$ of Y-27632 before incubation with compounds. Stock solutions were made by dissolving agents in DMSO, with a final concentration of DMSO less than $0.5 \%$ in media. After treatment, the cells were fixed and permeabilized via the addition of a solution that comprised $4 \%$ paraformaldehyde and $0.5 \%$ Triton X (Sigma-Aldrich) in PBS. Microtubules were detected using mouse anti-a-tubulin 
antibody (Sigma-Aldrich) followed by incubation with FITC-conjugated goat anti-mouse IgG (Jackson ImmunoResearch, West Grove, PA), actin fibers were stained using Texas-red conjugated phalloidin (Invitrogen), and nuclear staining was carried out with DAPI. Focal adhesions were stained with anti-vinculin antibody (Invitrogen) and FITC-conjugated goat anti-mouse IgG (Jackson ImmunoResearch). Focal adhesion kinase (FAK) and myosin light chain (MLC) phosphorylation were stained with anti-pFAK ${ }^{\mathrm{Y} 397}$ antibody (Abcam, Cambridge, MA) and anti-pMLC (Ser18/Thr19) antibody (Cell Signaling, Beverly, MA) respectively, with FITC and Cy5 conjugated goat anti-rabbit secondary antibodies (Jackson ImmunoResearch). Fluorescence and phase contrast images were collected using an Olympus FV 1000 confocal microscope and Olympus fluoview software (Olympus Imaging America Inc., Center Valley, PA) using a 60x oil immersion objective.

\subsection{Western Blotting}

Activated HUVECs were grown on collagen I coated T75 flasks to approximately $70 \%$ confluence and treated with $1 \mu \mathrm{M}$ OXi8006 for defined periods of time. A higher cell confluence was required to obtain sufficient protein, and with these conditions, a higher OXi8006 concentration was required to obtain similar effects to the morphology experiments on cover slips. OXi8006 was removed, and cells were briefly washed twice with $5 \mathrm{~mL}$ of ice cold PBS. Whole cell lysates were prepared by adding $400 \mu \mathrm{L}$ of lysis buffer per flask (50 mM tris base, $2 \%$ SDS, $10 \%$ glycerol, $50 \mathrm{mM}$ DTT), one protease inhibitor cocktail tablet (1 per $10 \mathrm{~mL}$, cOmplete ULTRA Tablets ${ }^{\mathrm{TM}}$, Roche, Indianapolis, IN), and one phosphatase inhibitor cocktail tablet (1 per $10 \mathrm{~mL}$, PhoSTOPTM, Roche). Lysates were sonicated (Misonix Sonicator 3000, Thermo-Fischer, Pittsburgh, PA) and protein concentrations determined via a Bradford assay. Lysates ( $45 \mu \mathrm{g}$ protein/sample) were combined with NUPAGETM loading dye and $500 \mathrm{mM}$ DTT solution, separated on NUPAGETM 4-12\% Bis-Tris gels (Invitrogen) and electroeluted to Immobilon-PTM PVDF membranes (EMD Millipore). Membranes were incubated with primary antibodies for pFAK $^{\mathrm{Y} 397}$ (Abcam), FAK (Cell Signaling), pMLC (Cell Signaling), and $\beta$-actin (SigmaAldrich). Anti-rabbit HRP and anti-mouse HRP secondary antibodies were obtained from Jackson ImmunoResearch. Protein bands were visualized using ECL Prime ${ }^{\mathrm{TM}}$ blotting detection reagent (GE, Piscataway, NJ) and ImageQuant LAS 4000 imaging system (GE). Analysis of bands was done using Licor Image Studio 4.0 software.

\subsection{Cell Cycle Analysis by Flow Cytometry}

HUVECs were plated into collagen-I coated 6-well plates (Corning) at a concentration of 200,000 cells/well. Cells were allowed to adhere for $48 \mathrm{~h}$ before a $24 \mathrm{~h}$ incubation period with compounds. Cells were trypsinized and then centrifuged at $800 \mathrm{~g}$ for 10 minutes. After suspension in PBS, the cells were fixed with $70 \%$ ethanol and incubated overnight at $-20^{\circ} \mathrm{C}$. Fixed cells were centrifuged at $800 \mathrm{~g}$ to remove ethanol and then resuspended in a PBS solution containing RNase A (20 $\mu \mathrm{g} / \mathrm{mL})$ and stained with propidium iodide (PI) $(20 \mu \mathrm{g} /$ $\mathrm{mL}$ ). DNA content was measured using a FACSCalibur flow cytometer (Becton-Dickinson, San Jose, CA), and data were analyzed using CellQuest software (Becton-Dickinson). 


\subsection{Cytotoxicity Assay}

The sulforhodamine B (SRB) assay was used to assess inhibition of human cell line growth as previously described [21, 25, 26]. Briefly, HUVECs and MDA-MB-231 cells were plated at 9,000 cells/well in 96-well plates (Corning) and incubated for $24 \mathrm{~h}$ or for $48 \mathrm{~h}$ (for a quiescent/confluent HUVEC population). Ten-fold serial dilutions of the compounds to be tested were then added to the wells. After $48 \mathrm{~h}$ of treatment, the cells were fixed with trichloroacetic acid, stained with SRB dye (Acid Red 52) (TKI, Tokyo), and dried. The dye was solubilized with $10 \mathrm{mM}$ Tris base solution and plates were read at $540 \mathrm{~nm}$ with an automated Biotek Elx800 plate reader (Biotek, Winooski, VT). Absorbance values were then normalized to $630 \mathrm{~nm}$ to account for background absorbance [27]. A growth inhibition of $50 \%\left(\mathrm{GI}_{50}\right.$ or the drug concentration causing a $50 \%$ reduction in the net protein staining relative to controls) was calculated from optical density data with Excel software. Dose response curves were generated using Graphpad Prism 5.0.

\subsection{Endothelial Tube Disruption Assay}

HUVECs were plated in 24-well culture plates (Corning) that had been coated with $0.5 \mathrm{~mL}$ of $9.5 \mathrm{mg} / \mathrm{mL}$ Matrigel ${ }^{\mathrm{TM}}$ (Becton-Dickinson). Cells were plated at a concentration of 124,000 cells/well, at $37^{\circ} \mathrm{C}$ for $16 \mathrm{~h}$ in M200 supplemented with a high growth factor supplement kit. After $16 \mathrm{~h}$, tube disruption was induced by treatment with varying concentrations of compounds for $2 \mathrm{~h}$, after which the compound was removed and the cells were washed twice with fresh M200. Cells were imaged using an Axiovert 40 CFL inverted microscope (Zeiss, Thornwood, NY) at 5X magnification, and bright field images were collected with negative contrast using a Canon Powershot A640 digital camera mounted onto the microscope.

\subsection{In Vivo Tumor Model}

Human breast cancer cells, MDA-MB-231 (ATCC), were transfected with a lentivirus containing a firefly luciferase reporter. Highly expressing stable clones were isolated to create the cell line, MDA-MB-231-Luc [28]. Induction of tumors was carried out by injecting $10^{6}$ cells mixed with $30 \%$ Matrigel $^{\mathrm{TM}}$ (BD Biosciences, San Jose, CA) into the mammary fat pads of female SCID mice (University of Texas Southwestern Medical Center). Tumors were allowed to grow to approximately $5 \mathrm{~mm}$ in diameter, determined by caliper, before selection for BLI or histological analysis. All animal procedures were carried out in accordance with the Guide for the Care and Use of Laboratory Animals as adopted and promulgated by the U.S. National Institutes of Health as well as the Institutional Animal Care and Use Committee approved protocols (University of Texas Southwestern Medical Center).

\subsection{In Vivo Bioluminescence Imaging}

Bioluminescence imaging was carried out as described previously [28]. Briefly, anaesthetized, tumor bearing mice $\left(\mathrm{O}_{2}, 2 \%\right.$ isoflurane, Henry Schein Inc., Melville, NY) were injected subcutaneously in the fore-back neck region with $80 \mu \mathrm{L}$ of a solution of luciferase substrate, $D$-luciferin (sodium salt, $120 \mathrm{mg} / \mathrm{kg}$, in saline, Gold Biotechnology, St. Louis, MO). Mice were maintained under anesthesia ( $2 \%$ isoflurane in oxygen, $1 \mathrm{dm}^{3} / \mathrm{min}$,) 
while baseline bioluminescence imaging was performed using a Xenogen IVIS® Spectrum (Perkin-Elmer, Alameda, CA). A series of BLI images was collected over 35 minutes using the following settings: auto exposure time, $\mathrm{f}$-stop $=2$, Field of view $=\mathrm{D}$, binning $=4$ (medium). Light intensity-time curves obtained from these images were analyzed using Living Image ${ }^{\circledR}$ software. Mice were injected intraperitoneally with either $120 \mu \mathrm{l}$ of saline (vehicle) or with OXi8007 in saline immediately after baseline BLI. Bioluminescence imaging was repeated, with new luciferin injections 2, 6 and $24 \mathrm{~h}$ later. Dose escalation studies using varying concentrations of OXi8007 (200-400 mg/kg) with three mice per concentration were performed except for $300 \mathrm{mg} / \mathrm{kg}$ where $\mathrm{n}=2$. Subsequently, a separate cohort of mice $(\mathrm{n}=5)$ was treated with OXi8007 in saline $(350 \mathrm{mg} / \mathrm{kg})$ via intraperitoneal injection. BLI was again repeated for this cohort of mice after 2, 6 and $24 \mathrm{~h}$. For comparison, other cohorts $(\mathrm{n}=5)$ of tumor bearing mice were treated with CA4P $(120 \mathrm{mg} / \mathrm{kg})$ or saline (control) IP and BLI was performed in a similar manner.

\subsection{Immunohistochemistry}

Histological analysis of tumor perfusion was carried out as previously described [29]. Tumor bearing mice were injected with saline or OXi8007. At each time point after injection (2, 6 and $24 \mathrm{~h})$, the blue fluorescent dye Hoechst $33342(10 \mathrm{mg} / \mathrm{kg}$, Molecular Probes by Life Technologies, Eugene, OR) was injected into the tail vein of anaesthetized mice and the tumors were excised after 1 minute. Excised tumors were flash frozen in liquid nitrogen and stored at $-80{ }^{\circ} \mathrm{C}$. A series of $6 \mu \mathrm{m}$ sections from several regions of each tumor was collected, and the cryosections were immunostained with antibodies to the endothelial marker CD31, diluted 1:200 (BD Pharmingen, Purified Rat Anti-mouse CD31) followed by Cy3-conjugated secondary antibody 1:1000 (Jackson ImmunoResearch), and also stained with Hoechst 33342. Tumor sections were imaged with a Zeiss Axio Scan Z1 confocal microscope using a 20X objective, and processed using ZEN 2012 software.

\subsection{Statistical Methods}

Data from the SRB assay are presented as mean \pm S.D. of a minimum of three independent experiments. Data from analysis of western blots are presented as mean \pm S.E.M. of a minimum of three independent experiments. In order to determine significant differences between treatment and control values, the Student's two-tailed $t$ test was used, with analyses performed using Graphpad Prism 5.0. Analysis of dynamic BLI data was performed using Living Image software. Signal intensity was measured for regions of interest in tumors following luciferin injection, and maximum intensity was determined. Mean values \pm S.D. are presented for cohorts of tumors and statistical significance was assessed using an analysis of variance (ANOVA) on the basis of Fisher's Protected Least Significant Difference (PLSD; Statview, SAS Institute, Inc., Cary, NC, USA). ANOVA was applied for comparison of multiple repeat measurements and the PLSD examined the importance of individual measurements on the overall population. Statistically significant data are denoted by: ${ }^{*} p<0.05, * * p<0.01$, and $* * * p<0.001$. 


\section{Results}

\subsection{OXi8006 Treatment Resulted in Profound Cytoskeletal Changes in Endothelial Cells}

One characteristic of tubulin-binding VDAs is their disruption of cellular microtubules and a subsequent increase in actin stress fiber formation [30]. In tumor endothelium, this is followed by cell contraction and detachment from the substratum [31]. Indirect immunofluorescence staining showed that $10 \mathrm{nM}$ OXi8006 caused disruption of microtubules in activated, rapidly proliferating HUVECs (grown in high growth factor containing VEGF, EGF, bFGF, IGF-1, and 2\% FBS supplemented medium) used to model the tumor endothelium [22-24]. Starting at 5 minutes and progressing over the course of $2 \mathrm{~h}$ (Fig. 2A), a profound loss of the microtubule network was observed. This was followed by actin cytoskeletal changes (starting approximately 30 minutes after treatment), as observed via Texas-Red conjugated phalloidin staining of F-actin (Fig. 2B). F-actin in untreated cells is mainly found in bands in the cortical region at the periphery of cells as well as in a few fine filaments throughout the cell with some stress fibers observed. Microtubule disruption as effected by OXi8006 treatment resulted in significant formation of stress fibers across the cell body. At $10 \mathrm{nM}$ OXi8006 concentration, a little over $50 \%$ of cells showed extensive stress fiber formation after $1 \mathrm{~h}$, while at $2 \mathrm{~h}$ approximately $90 \%$ of cells showed this effect. HUVEC cytoskeletal elements also responded to OXi8006 treatment in a dose dependent manner, with effects beginning at $10 \mathrm{nM}$, and increasing at $20 \mathrm{nM}$ (Supplemental Figs. S1 and Fig. S2). Treatment with $100 \mathrm{nM}$ OXi8006 for $2 \mathrm{~h}$ resulted in approximately $90 \%$ of HUVECs showing maximal stress fiber formation, with the remaining cells completely retracted from the substrate. HUVECs treated with OXi8006 $(1 \mu \mathrm{M})$ for $1 \mathrm{~h}$ demonstrated extensive cell contraction and rounding, as well as release of cells from the gelatin layer, with significant blebbing also observed in some cells (Supplemental Fig. S4). Treatment of HUVECs with OXi8007 showed similar effects although at higher concentrations (Supplemental Fig. S3).

\subsection{OXi8006 Treatment Increased HUVEC Contractility through Increased Myosin Light Chain Phosphorylation}

Non-muscle myosin II plays an important role in actin bundling into stress fibers and the cell contractile system, and its activity is mediated via phosphorylation of the regulatory light chains of this protein. To examine the effects of OXi8006 on MLC signaling in HUVECs, western blot analysis was performed with an antibody to MLC phosphorylated at Thr-18 and Ser-19. After treatment of activated, subconfluent HUVECs with $1 \mu \mathrm{M}$ OXi8006, an increase in MLC phosphorylation over time was observed, with maximal phosphorylation occurring at approximately 30 minutes followed by a decrease in phosphorylation (Fig. 3A, B). Indirect immunofluorescence staining of subconfluent HUVECs treated with $100 \mathrm{nM}$ OXi8006 also showed increased MLC phosphorylation, with pMLC co-localizing with OXi8006 induced actin stress fibers (Fig. 3E).

\subsection{OXi8006 Treatment Induced an Increase in Focal Adhesion Formation and Focal Adhesion Kinase Signaling}

Focal adhesions are assemblies of proteins that link actin stress fibers through integrins to the extracellular matrix. The formation of focal adhesions is a key component of cytoskeletal 
contractility and cellular adhesion [32-34]. Vinculin, a scaffolding protein that is recruited to focal adhesions, was used to assess the formation of focal adhesions by indirect immunofluorescence staining. OXi8006 induced microtubule disruption led to increased focal adhesion formation (as shown by an increase in vinculin staining (Supplemental Fig. S5)) localized to the ends of actin stress fibers (as seen from the merged images (Supplemental Fig.S5)). Focal adhesion kinase (FAK) activation through phosphorylation is a crucial step in the control of focal adhesion formation and turnover [32, 35]. Treatment with OXi8006 resulted in a concentration and time dependent downstream increase in FAK phosphorylation at Tyr-397 as observed via western blotting (Fig. 3C and D) and immunofluorescence staining (Fig. 3F). Western blotting showed an initial increase in phosphorylation occurring about 3 minutes after treatment, with maximal phosphorylation seen approximately 30-60 minutes after treatment followed by a decrease in phosphorylation.

\subsection{OXi8006 Induced Changes in HUVEC Contractility and Adhesion were Mediated via RhoA}

Previous studies implicated the intracellular switch RhoA and its downstream effector RhoA kinase (ROCK) in the mechanism of VDA action [1]. In order to ascertain whether the RhoA signaling pathway is needed for the changes in HUVEC contractility and adhesion caused by OXi8006 treatment, the effects of Y-27632 (a compound that inhibits the activity of ROCK [36]) on OXi8006 mediated cytoskeletal changes were examined. Pre-treatment of cells with Y-27632 prevented OXi8006 induced formation of actin stress fibers and focal adhesions (Fig. 4 A , C), and reduced the basal levels of actin bundling and focal adhesion formation in untreated HUVECs. However, pre-treatment with Y-27632 had no effect on microtubule disruption caused by OXi8006 treatment (Fig. 4 B). Application of Y-27632 also prevented the OXi8006 induced increase in MLC phosphorylation (Supplemental Figs. S6 and Fig. S7). This demonstrated that inhibition of ROCK abrogates the downstream effects associated with OXi8006 induced microtubule disruption and highlights the importance of RhoA in this signaling pathway.

\subsection{Cytotoxicity and Cell Cycle Effects of OXi8006 and OXi8007}

The cytotoxicity of OXi8006 and OXi8007 was evaluated against rapidly proliferating, subconfluent HUVECs to model the activated tumor endothelium and compared to nearly confluent HUVECs as representative of the low proliferating baseline of normal mature endothelium. Cytotoxicity was evaluated using the standard SRB assay, and results showed that OXi8006 and its corresponding prodrug salt OXi8007 caused significant inhibition of cell growth of activated HUVECs (grown in medium supplemented with a high growth factor kit). The $\mathrm{GI}_{50}$ values were in the low nanomolar range (Table 1). When HUVECs were grown to near confluence, there was a significant decrease in the cytotoxicity associated with OXi8006 treatment. Cytotoxicity reached a plateau and did not increase beyond 50\% inhibition of cell growth, even at very high OXi8006 concentrations (> 100 $\mu \mathrm{M})$. Similar effects were observed for OXi8007 treatment of confluent HUVECs (Supplemental Fig. S8). The activity of OXi8006 and its corresponding prodrug salt OXi8007 were most effective on the most activated HUVECs. A progressive loss of activity was observed as the level of HUVEC confluence increased. OXi8006 and OXi8007 also 
caused significant inhibition of proliferation of the human triple negative breast cancer cell line MDA-MB-231 (Table 1).

One characteristic feature of tubulin-binding VDAs is their ability to induce antimitotic effects via blockade at the $\mathrm{G} 2 / \mathrm{M}$ phase of the cell cycle with longer term exposure. HUVECs were treated with vehicle (0.5\% DMSO in media), OXi8006 $(0.01-0.1 \mu \mathrm{M})$, and OXi8007 $(0.025-1 \mu \mathrm{M})$ for $24 \mathrm{~h}$. Analysis of the HUVEC DNA profiles via flow cytometry showed that OXi8006 and OXi8007 treatment caused a pronounced increase in the percentage of cells blockaded at G2/M (4N DNA content) as compared with the amounts in the vehicle treated cells (Fig. 5).

\subsection{OXi8006 Treatment Resulted in a Disruption of Pre-established Vascular Networks}

A property of endothelial cells is their ability to form a network of capillary tubes when plated at sub-confluent concentrations in the presence of an extracellular matrix and appropriate growth factors [22]. Upon plating on a dense coat of Matrigel ${ }^{\mathrm{TM}}$, HUVECs attach and generate mechanical forces on the surrounding extracellular support matrix to create tracks or guidance pathways that facilitate cellular migration, eventually resulting in the formation of a network of cells (Fig. 6) which models neovasculature in two dimensions. This network retains the sensitivity to growth factors and VDAs that exists in the tumor vessels but is mostly absent in remodeled normal vasculature. Exposure of this endothelial tube network to OXi8006 caused a concentration-dependent disruption that resulted in rounded disorganized groups of endothelial cells (Fig. 6). OXi8006 treatment resulted in significant effects at $0.1 \mu \mathrm{M}$ with complete destruction of the network observed upon $1 \mu \mathrm{M}$ treatment (Fig. 6). OXi8007 demonstrated significant disruption at $1 \mu \mathrm{M}$ (Supplemental Fig.S9).

\subsection{In vivo Bioluminescence Imaging of the Vascular Disrupting Effects of OXi8007 in a Human Breast Cancer Xenograft in Mice}

Tumor vascular disruption blocks the flow of the luciferin substrate to the tumor and results in a quantifiable decrease in bioluminescence signal $[2,29]$. For control tumors maximum signal correlated with tumor size. At a volume of approximately $110 \mathrm{~mm}^{3}$ tumors were evaluated for signal response to OXi8007. Following administration of luciferin substrate to the SCID mice bearing orthotopic luciferase-transfected MDA-MB-231 human breast cancer cells, bioluminescence signal was observed, which increased reaching a maximum intensity after 15-20 minutes followed by a gradual decline over the next 15 minutes (Fig. 7A, baseline). Repeat measurements in the control group showed no significant difference in signal over a period of $24 \mathrm{~h}$. However, dose-escalation with OXi8007 (200-400 mg/kg) demonstrated a dose-dependent decrease in maximum bioluminescence at $6 \mathrm{~h}$ after treatment (Fig. 7 A , B). At each dose the tumors showed significantly lower mean maximum signal at 6 and $24 \mathrm{~h}$ compared with the same tumors at baseline ( $<<0.05$; Fig. 7 A, B and C). At 6 h each group showed significantly lower signal than the controls, though at $24 \mathrm{~h}$ only the 350 $\mathrm{mg} / \mathrm{kg}$ group remained significantly different from controls. Thus, a dose of $350 \mathrm{mg} / \mathrm{kg}$ was found to be effective and well tolerated by the mice. Dynamic BLI was then used to compare the time dependent effect of OXi8007 versus CA4P (positive VDA control) or saline control on MDA-MB-231-luc xenografts growing in the mammary fat pad in a cohort of mice $(n=5$ 
each; Fig. 8). BLI was evaluated before and after (2, 6, and $24 \mathrm{~h})$ administration of VDA or saline. Fresh luciferin was administered on each occasion. Saline gave quite reproducible results with no significant changes in light intensity over $24 \mathrm{~h}$ (Fig. 8B, C) in terms of light distribution, maximum light intensity, and time to maximum light emission. Administration of OXi8007 (350 mg/kg, Fig. 8A, B) induced a decrease in normalized signal within $2 \mathrm{~h}$ by approximately $84 \%$ ( $<<0.001$ vs. baseline), with a further decrease to a value of only $7 \%$ of that of the baseline when fresh luciferin was administered at the $6 \mathrm{~h}$ time point ( $\mathrm{p}<0.001 \mathrm{vs}$. baseline). The bioluminescence emission remained significantly depressed for $24 \mathrm{~h}$ (by $87 \%$ ) (p<0.001 vs. baseline), although some recovery was observed when compared to the 6 $\mathrm{h}$ time point. The results were compared to BLI of tumors in mice treated with CA4P (120 $\mathrm{mg} / \mathrm{kg}$ ), a vascular disrupting agent in clinical trials which we have previously verified to cause vascular shutdown in various tumors based on comparison of dynamic BLI, histology and MRI [29, 37]. OXi8007 treatment resulted in significantly less recovery of BLI signal between 6 and $24 \mathrm{~h}$ than CA4P treatment $(\mathrm{p}<0.05)$ (Fig. 8D).

\subsection{Histological Confirmation of Decreased Tumor Perfusion after OXi8007 Treatment}

To determine perfused vasculature, the fluorescent DNA-binding dye Hoechst 33432, which is rapidly taken up by vascular endothelial cells, was injected into mice at various time points $(0,6$, and $24 \mathrm{~h}$ ) after treatment (Fig. 9). Histology showed extensive perfusion of the pre-treated tumor (saline vehicle control) with a well-developed tumor vasculature as seen from CD31 (red) immunofluorescence staining. Tumor sections taken after treatment of mice with OXi8007 (350 mg/kg) showed lower intensity and distribution of the Hoechst perfusion marker (blue) by $6 \mathrm{~h}$ and only peripheral perfusion after $24 \mathrm{~h}$. This reduction in perfusion was accompanied by a loss of endothelial cells or a reduction in tumor blood vessel diameter as confirmed by reduced CD31 immunofluorescence at $6 \mathrm{~h}$ which was further decreased at $24 \mathrm{~h}$ with the exception of the viable outer rim of the tumor. These results are consistent with significant vascular disruption.

\section{Discussion}

In order to demonstrate the vascular disrupting properties and elucidate the mechanism of action of OXi8006 (the proposed mechanism is shown in Fig. 10), we performed a series of biochemical and biological experiments in HUVECs. The dynamic assembly and disassembly of microtubules is essential for cell growth, motility, and signaling, thus making it an important anticancer target. OXi8007 is dephosphorylated by non-specific phosphatases, and the effector anti-cancer agent (OXi8006) is proposed to enter cells by simple diffusion (Fig. 10). In a dose-and time-dependent manner, OXi8006 treatment resulted in microtubule disruption in rapidly proliferating endothelial cells as determined by immunofluorescence confocal microscopy. At a minimal effective concentration of $10 \mathrm{nM}$, OXi8006 treatment caused significant disruption of microtubules in HUVECs, which started within 5 minutes and progressed over the course of $2 \mathrm{~h}$ to a profound loss of the microtubule network (Fig. 2)

In untreated or vehicle-treated HUVECs, actin is primarily visualized as filaments in the cortical layer at the cell periphery along with a baseline level of thick bundles of actin 
filaments (stress fibers) that are linked to the cell substratum through focal adhesions. Microtubule disruption, effected by OXi8006 treatment of rapidly proliferating endothelial cells, led to a dose- and time-dependent increase in actin stress fiber formation. With a higher concentration $(1 \mu \mathrm{M})$ of OXi8006 treatment, significant blebbing occurred in some cells, and extensive contraction (rounding up) and detachment from the gelatin layer was observed by fluorescence confocal and light microscopy, processes that precede VDA induced apoptosis [38]. Antiparallel actin bundling into stress fibers is aided by a number of actin binding proteins that play a role in the cell contractile and force generation system. One essential member of this group of proteins is non-muscle myosin II (NM II) which binds and contracts filamentous actin in an ATP-dependent process. Comprised of three pairs of peptides, the two heavy chains of NM II assemble into a long a-helical coiled coil that forms an extended rod-shaped domain and two globular head groups with binding sites for both ATP and actin. The two essential light chains stabilize the heavy chain structure while phosphorylation of its two regulatory light chains at Thr-18 and Ser-19 mediate NM II activation [39]. Activation of NM II is associated with a conformational change leading to its assembly into bipolar filaments through interactions between the rod domains which bind to actin through their head groups, resulting in contractile myosin linked antiparallel actin stress fibers. We observed, by confocal immunofluorescence microscopy, that OXi8006 treatment (100 nM) led to increased phosphorylation of MLC and activation of NM II. This resulted in an increase in stress fiber formation. An examination by western blotting confirmed this increase in phosphorylation of MLC with a maximum occurring at 30 min post-treatment with $1 \mu \mathrm{M}$ OXi8006.

Focal adhesions are super assemblies of proteins that form at sites of tight adhesion linking the actin cytoskeleton through integrins to the extracellular matrix. They are made up of integrins and cytoskeletal and signaling proteins such as talin, a-actinin, vinculin, zyxin, paxillin, and focal adhesion kinase (FAK) among other components [33] and increase in response to contraction of the actin-myosin cytoskeleton. An increase in focal adhesions, localized to the ends of actin stress fibers, was observed as determined by anti-vinculin immunofluorescence upon OXi8006 treatment of activated HUVECs. FAK plays significant regulatory and structural roles during focal adhesion reorganization. Regulation of FAK includes phosphorylation at multiple tyrosine and serine residues. Tyrosine 397 is the initial phosphorylation site of FAK and is involved in its activation [32, 40, 41]. Therefore, we examined the phosphorylation of FAK at this site and found that it increased in a concentration and time dependent manner in response to microtubule disruption as a consequence of OXi8006 treatment.

RhoA is a guanidine triphosphatase that regulates a number of cellular processes, including actin dynamics, cell contractility, and cell adhesion. Previous studies have shown that RhoA plays a significant role in focal adhesion regulation via FAK signaling [35, 42, 43].. Upon dissociation of GDP, RhoA binds GTP and activates Rho-associated kinase (ROCK), which in turn can increase the level of phosphorylation of myosin via direct phosphorylation of the regulatory light chain and/or by phosphorylation and inactivation of MLC phosphatase [44, 45]. In order to ascertain whether OXi8006 functions via this mechanism, activated HUVECs were treated with the RhoA kinase (ROCK) inhibitor Y-27632 prior to OXi8006 treatment. 
Pretreatment of HUVECs with Y-27632 did not inhibit microtubule disruption upon OXi8006 treatment, but it effectively inhibited the increase in actin stress fiber formation and myosin regulatory light chain phosphorylation. We also determined that pretreatment with Y-27632 prevented the increase in FAK phosphorylation (pY397) previously observed with OXi8006. Consistent with the activity and mechanism of action of a tubulin-binding VDA [1, 5, 30], we have confirmed the role of the intracellular switch RhoA and its downstream effector RhoA kinase in the proposed OXi8006 mechanism (Fig. 10). We have also demonstrated the importance of FAK phosphorylation (pY397) in the tubulin-binding VDA mechanism. These studies provided support for the proposed mechanism of OXi8007 action depicted in Fig. 10.

An evaluation of the cytotoxicity using the standard SRB assay showed that OXi8006 and its corresponding prodrug salt OXi8007 caused significant inhibition of proliferation of activated HUVECs with $\mathrm{GI}_{50}$ values in the low nanomolar range (Table 1). However, when HUVECs were grown to near confluence before treatment as a model for the low proliferating baseline of normal mature endothelium, there was a significant decrease in the cytotoxicity of OXi8006 and its prodrug OXi8007. These results suggest selectivity of OXi8006 and OXi8007 towards rapidly proliferating endothelial cells. These compounds were also very potent against MDA-MB-231 breast cancer cells consistent with their activity on other cancer cell lines [17, 21]. In separate experiments, the tubular capillary network that models tumor neovasculature that is formed by HUVECs plated on Matrigel ${ }^{\mathrm{TM}}$ was disrupted by OXi8006 in a concentration dependent manner as endothelial cells retracted and rounded up. The network of HUVEC tube structures began to break down after treatment with $0.1 \mu \mathrm{M}$ OXi8006 and was completely disrupted at a concentration of $1 \mu \mathrm{M}$. Related to the microtubule disruption activity and cytotoxicity toward cancer cell lines, OXi8006 is an antimitotic agent and induced a cell cycle blockade at G2/M as determined by flow cytometry of activated HUVECs treated with OXi8006 for $24 \mathrm{~h}$. This transition from cell populations mostly at G1 to a majority of cells at G2/M occurred between 25 and $50 \mathrm{nM}$ OXi8006. OXi8007 treatment of HUVECs showed a similar effect but at a higher concentration (between 100 and $250 \mathrm{nM}$ ).

Dynamic bioluminescence imaging is a convenient and effective method to evaluate VDAs in luciferase-expressing cells growing as tumor xenografts in mice [2, 28, 29]. Tumor vascular disruption blocks the delivery of the luciferin substrate to the tumor and results in a quantifiable decrease in bioluminescence signal. From dose escalation studies assessed by BLI in xenograft SCID mice, $350 \mathrm{mg} / \mathrm{kg}$ of the water-soluble phosphate prodrug OXi8007 was determined to be the dose that was effective and well tolerated. At this dose, we demonstrated that OXi8007 was a potent VDA in a cohort of mice bearing xenograft tumors of luciferase-transfected human triple negative breast cancer (MDA-MB-231-luc) assessed by BLI. A decrease of $84 \%$ in normalized signal was observed within $2 \mathrm{~h}$, with a further decrease (corresponding to $93 \%$ total loss) observed at the $6 \mathrm{~h}$ time point. Although there was some recovery at the $24 \mathrm{~h}$ time point, it was significantly less than what was observed with CA4P treatment, a VDA in human clinical trials $[14,15]$, used here for comparison. The in vivo BLI results of vascular disrupting activity that were observed after OXi8007 treatment were confirmed by histology. As with other VDAs [46], a persistent "viable rim" of tumor perfusion was observed at the interface of the tumor with normal tissue where the 
vasculature more closely resembles normal vasculature and which is largely unaffected by VDA action. The viable rim is the site where tumor regrowth is most likely to take place after VDA treatment. The BLI findings with OXi8007 are consistent with the previously observed acute selective tumor vascular shutdown using Color-Doppler ultrasound in a mouse bearing a PC-3 human prostate xenograft [17]. They also match longer term observations in separate cohorts of MDA-MB-231-luc breast tumor bearing mice, which showed severe vascular impairment and hypoxiation by MRI within $4 \mathrm{~h}$ and significantly diminished BLI signal up to $72 \mathrm{~h}$ [47]. By contrast, limited effects were seen with OXi8007 in Ewing's sarcoma family (TC-32) of tumors [19], but that study used a lower dose of OXi8007 (200 mg/kg), which we have seen to be considerably less effective (Fig. 7). Through in vivo dynamic BLI and biochemical and biological experiments on activated endothelial cells, we have demonstrated that OXi8006 and its phosphate prodrug OXi8007 have potent VDA activity. Taken together these results indicate that the prodrug OXi8007 is a very promising VDA that warrants further pre-clinical evaluation.

\section{Supplementary Material}

Refer to Web version on PubMed Central for supplementary material.

\section{Acknowledgments}

The authors thank Dr. A. Ramirez (Mass Spectrometry Core Facility, Baylor University) and Dr. J. Karban, Dr. C. Moehnke and Dr. M. Nemec (Director) for use of the shared Molecular Biosciences Center at Baylor University. Dr. Kate Luby-Phelps provided invaluable assistance with fluorescent microscopy in the Microscopy Resource of the Cancer Center at UT Southwestern Medical Center. This work was supported by the National Institutes of Health National Cancer Institute [Grant 5R01CA140674] (to K.G.P. and M.L.T. with subcontract to R.P.M.), and OXiGENE, Inc. (Grant to K.G.P. and M.L.T). The content is solely the responsibility of the authors and does not necessarily represent the official views of the National Cancer Institute or the National Institutes of Health. Imaging was facilitated with the assistance of Resources of the Harold C. Simmons Cancer Center supported through an National Institutes of Health National Cancer Institute Cancer Center Support Grant [Grant 1P30 CA142543], specifically, the Southwestern Small Animal Imaging Resource, and Live Cell Imaging Resource. The IVIS Spectrum was purchased with support of 1S10RR024757.

\section{Abbreviations}

$\begin{array}{ll}\text { ANOVA } & \text { analysis of variance } \\ \text { BLI } & \text { bioluminescence imaging } \\ \text { CA4 } & \text { combretastatin A-4 } \\ \text { CA4P } & \text { combretastatin A-4 phosphate } \\ \text { DAPI } & 4, \text {, 6-diamidino-2-phenylindole } \\ \text { DMSO } & \text { dimethyl sulfoxide } \\ \text { DTT } & \text { dithiothreitol } \\ \text { FAK } & \text { focal adhesion kinase } \\ \text { FDA } & \text { Federal Drug Administration } \\ \text { FITC } & \text { fluorescein isothiocyanate }\end{array}$


GI50 median growth inhibitory concentration

HRP horseradish peroxidase

HUVEC human umbilical vein endothelial cells

MLC

myosin light chain

NMII

non-muscular myosin II

OXi8006

2-(3'-hydroxy-4'-methoxyphenyl)-3-(3",4",5"'-trimethoxybenzoyl)-6, methoxyindole

OXi8007 2-(3'-disodium phosphate-4'-methoxyphenyl)-3-(3", $4^{\prime \prime}, 5^{\prime \prime}-$

trimethoxybenzoyl)-6-methoxyindole

PBS phosphate buffered saline

PI propidium iodide

PLSD protected least significant difference

PMLC phosphorylated myosin light chain

ROCK RhoA kinase

SCID severe combined immunodeficiency

SDS sodium dodecyl sulfate

SRB sulforhodamine B

VDA vascular disrupting agent

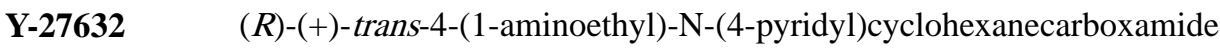
dihydrochloride

\section{References}

1. Kanthou C, Tozer GM. The tumor vascular targeting agent combretastatin A-4-phosphate induces reorganization of the actin cytoskeleton and early membrane blebbing in human endothelial cells. Blood. 2002; 99:2060-2069. [PubMed: 11877280]

2. Mason RP, Zhao D, Liu L, Trawick ML, Pinney KG. A perspective on vascular disrupting agents that interact with tubulin: preclinical tumor imaging and biological assessment. Integr. Biol. 2011; 3:375-387.

3. Siemann DW, Horsman MR. Vascular targeted therapies in oncology. Cell Tissue Res. 2009; 335:241-248. [PubMed: 18752004]

4. Chaplin DJ, Dougherty GJ. Tumour vasculature as a target for cancer therapy. Br. J. Cancer. 1999; (80 Suppl 1):57-64. [PubMed: 10466764]

5. Tozer GM, Kanthou C, Baguley BC. Disrupting tumour blood vessels. Nat. Rev. Cancer. 2005; 5:423-435. [PubMed: 15928673]

6. Siemann DW, Bibby MC, Dark GG, Dicker AP, Eskens FALM, Horsman MR, Marmé D, LoRusso PM. Differentiation and definition of vascular-targeted therapies. Clin. Cancer Res. 2005; 11:416420. [PubMed: 15701823]

7. Bergers G, Song S, Meyer-Morse N, Bergsland E, Hanahan D. Benefits of targeting both pericytes and endothelial cells in the tumor vasculature with kinase inhibitors. J. Clin. Investig. 2003; 111:1287-1295. [PubMed: 12727920] 
8. Ren X, Dai M, Lin LP, Li PK, Ding J. Anti-angiogenic and vascular disrupting effects of C9, a new microtubule-depolymerizing agent. Br. J. Pharm. 2009; 156:1228-1238.

9. Jordan MA, Wilson L. Microtubules as a target for anticancer drugs. Nature reviews. Cancer. 2004; 4:253-265. [PubMed: 15057285]

10. Xu XP, Wu XD, Liang GL, Huang WS, Wang L, Jing HY, Zhong SL. Pharmacokinetics, excretion, and distribution of combretastatin A4 phosphate in rats. Die Pharmazie. 2012; 67:529-533. [PubMed: 22822542]

11. Shen CH, Shee JJ, Wu JY, Lin YW, Wu JD, Liu YW. Combretastatin A-4 inhibits cell growth and metastasis in bladder cancer cells and retards tumour growth in a murine orthotopic bladder tumour model. Br J Pharmacol. 2010; 160:2008-2027. [PubMed: 20649598]

12. Mita MM, Sargsyan L, Mita AC, Spear M. Vascular-disrupting agents in oncology. Expert Opin. Investig. Drugs. 2013; 22:317-328.

13. Zweifel M, Jayson G, Reed N, Osborne R, Hassan B, Shreeves G, Poupard L, Walicke PA, Balkissoon J, Chaplin DJ, Rustin G. Combretastatin A-4 phosphate (CA4P) carboplatin and paclitaxel in patients with platinum-resistant ovarian cancer: Final phase II trial results. J. Clin. Oncol. 2009; 27

14. Nathan P, Zweifel M, Padhani AR, Koh DM, Ng M, Collins DJ, Harris A, Carden C, Smythe J, Fisher N, Taylor NJ, Stirling JJ, Lu SP, Leach MO, Rustin GJ, Judson I. Phase I trial of combretastatin A4 phosphate (CA4P) in combination with bevacizumab in patients with advanced cancer. Clin. Cancer Res. 2012; 18:3428-3439. [PubMed: 22645052]

15. Rustin GJ, Shreeves G, Nathan PD, Gaya A, Ganesan TS, Wang D, Boxall J, Poupard L, Chaplin DJ, Stratford MR, Balkissoon J, Zweifel M. A Phase Ib trial of CA4P (combretastatin A-4 phosphate), carboplatin, and paclitaxel in patients with advanced cancer. Br. J. Cancer. 2010; 102:1355-1360. [PubMed: 20389300]

16. Sosa JA, Elisei R, Jarzab B, Bal CS, Koussis H, Gramza AW, Ben-Yosef R, Gitlitz BJ, Haugen B, Karandikar SM, Khuri FR, Licitra LF, Remick SC, Marur S, Lu C, Ondrey FG, Lu S, Balkissoon J. A randomized phase II/III trial of a tumor vascular disrupting agent fosbretabulin tromethamine (CA4P) with carboplatin (C) and paclitaxel (P) in anaplastic thyroid cancer (ATC): Final survival analysis for the FACT trial. J. Clin. Oncol. 2011; 29

17. Hadimani MB, MacDonough MT, Ghatak A, Strecker TE, Lopez R, Sriram M, Nguyen BL, Hall JJ, Kessler RJ, Shirali AR, Liu L, Garner CM, Pettit GR, Ernest H, Chaplin DJ, Mason RP, Trawick ML, Pinney KG. Synthesis of a 2-Aryl-3-aroyl Indole Salt (OXi8007) Resembling Combretastatin A-4 with Application as a Vascular Disrupting Agent. J. Nat. Prod. 2013; 76:16681678. [PubMed: 24016002]

18. Pinney, KG.; Pettit, GR.; Trawick, ML.; Jelinek, C.; Chaplin, DJ. The Development and Discovery of the Combretastatins. In: Cragg, GM.; Kingston, DGI.; Newman, DJ., editors. Antitumor Agents from Natural Products. Boca Raton, FL: CRC Press, Taylor and Francis Group; 2011. p. 227-263.

19. Dalal S, Burchill SA. Preclinical evaluation of vascular-disrupting agents in Ewing's sarcoma family of tumours. Eur. J. Cancer. 2009; 45:713-722. [PubMed: 19136249]

20. Pinney, KG.; Wang, F.; Hadimani, MB. Indole-containing and combretastatin-related anti-mitotic and anti-tubulin polymerization agents. US Patent US 6,849,656 B1. 2005 Feb 1. p. 2005

21. MacDonough MT, Strecker TE, Hamel E, Hall JJ, Chaplin DJ, Trawick ML, Pinney KG. Synthesis and biological evaluation of indole-based, anti-cancer agents inspired by the vascular disrupting agent 2-(3 '-hydroxy-4 '-methoxyphenyl)-3-(3 “,4 ",5 "-trimethoxybenzoyl)-6-methoxyindole (OXi8006). Bioorg. Med. Chem. 2013; 21:6831-6843. [PubMed: 23993969]

22. DeCicco-Skinner KL, Henry GH, Cataisson C, Tabib T, Gwilliam JC, Watson NJ, Bullwinkle EM, Falkenburg L, O'Neill RC, Morin A, Wiest JS. Endothelial cell tube formation assay for the in vitro study of angiogenesis. Journal of visualized experiments : JoVE. 2014:e51312. [PubMed: 25225985]

23. Zhou Q, Kiosses WB, Liu J, Schimmel P. Tumor endothelial cell tube formation model for determining anti-angiogenic activity of a tRNA synthetase cytokine. Methods. 2008; 44:190-195. [PubMed: 18241800] 
24. Patel NS, Li JL, Generali D, Poulsom R, Cranston DW, Harris AL. Up-regulation of delta-like 4 ligand in human tumor vasculature and the role of basal expression in endothelial cell function. Cancer research. 2005; 65:8690-8697. [PubMed: 16204037]

25. Vichai V, Kirtikara K. Sulforhodamine B colorimetric assay for cytotoxicity screening. Nat. Protoc. 2006; 1:1112-1116. [PubMed: 17406391]

26. Monks A, Scudiero D, Skehan P, Shoemaker R, Paull K, Vistica D, Hose C, Langley J, Cronise P, Vaigro-Wolff A, et al. Feasibility of a high-flux anticancer drug screen using a diverse panel of cultured human tumor cell lines. J. Natl. Cancer Inst. 1991; 83:757-766. [PubMed: 2041050]

27. Skehan P, Storeng R, Scudiero D, Monks A, McMahon J, Vistica D, Warren JT, Bokesch H, Kenney S, Boyd MR. New colorimetric cytotoxicity assay for anticancer-drug screening. J. Natl. Cancer Inst. 1990; 82:1107-1112. [PubMed: 2359136]

28. Liu L, Beck H, Wang X, Hsieh H-P, Mason RP, Liu X. Tubulin-destabilizing agent BPR0L075 induces vascular-disruption in human breast cancer mammary fat pad xenografts. PloS one. 2012; 7:e43314. [PubMed: 22937031]

29. Zhao D, Richer E, Antich PP, Mason RP. Antivascular effects of combretastatin A4 phosphate in breast cancer xenograft assessed using dynamic bioluminescence imaging and confirmed by MRI. FASEB J. 2008; 22:2445-2451. [PubMed: 18263704]

30. Kanthou C, Tozer GM. Tumour targeting by microtubule-depolymerizing vascular disrupting agents. Expert Opin. Ther. Targets. 2007; 11:1443-1457. [PubMed: 18028009]

31. Kremmidiotis G, Leske AF, Lavranos TC, Beaumont D, Gasic J, Hall A, O’Callaghan M, Matthews CA, Flynn B. BNC105: a novel tubulin polymerization inhibitor that selectively disrupts tumor vasculature and displays single-agent antitumor efficacy. Mol. Cancer Ther. 2010; 9:15621573. [PubMed: 20515948]

32. Schlaepfer DD, Hauck CR, Sieg DJ. Signaling through focal adhesion kinase. Prog. Biophys. Mol. Biol. 1999; 71:435-478. [PubMed: 10354709]

33. Sastry SK, Burridge K. Focal Adhesions: A Nexus for Intracellular Signaling and Cytoskeletal Dynamics. Exp. Cell Res. 2000; 261:25-36. [PubMed: 11082272]

34. Tolbert CE, Thompson PM, Superfine R, Burridge K, Campbell SL. Phosphorylation at Y1065 in Vinculin Mediates Actin Bundling, Cell Spreading, and Mechanical Responses to Force. Biochemistry. 2014; 53:5526-5536. [PubMed: 25115937]

35. Mitra SK, Hanson DA, Schlaepfer DD. Focal adhesion kinase: in command and control of cell motility. Nat. Rev. Mol. Cell Biol. 2005; 6:56-68. [PubMed: 15688067]

36. Narumiya, S.; Ishizaki, T.; Ufhata, M. Use and properties of ROCK-specific inhibitor Y-27632. In: Balch, CJDWE.; Alan, H., editors. Methods in enzymology. Academic Press; 2000. p. 273-284.

37. Liu L, Mason RP, Gimi B. Dynamic bioluminescence and fluorescence imaging of the effects of the antivascular agent Combretastatin-A4P (CA4P) on brain tumor xenografts. Cancer Lett. 2015; 356:462-469. [PubMed: 25305449]

38. Iyer S, Chaplin DJ, Rosenthal DS, Boulares AH, Li LY, Smulson ME. Induction of apoptosis in proliferating human endothelial cells by the tumor-specific antiangiogenesis agent combretastatin A-4. Cancer research. 1998; 58:4510-4514. [PubMed: 9788591]

39. Conti MA, Adelstein RS. Nonmuscle myosin II moves in new directions. J. Cell Sci. 2008; 121:11-18. [PubMed: 18096687]

40. Dahmani S, Reynaud C, Tesnière A, Rouelle D, Desmonts J-M, Mantz J. Lidocaine increases phosphorylation of focal adhesion kinase in rat hippocampal slices. Eur. J. Pharm. 2004; 489:5558.

41. Lim Y, Han I, Jeon J, Park H, Bahk Y-Y, Oh E-S. Phosphorylation of focal adhesion kinase at tyrosine 861 is crucial for Ras transformation of fibroblasts. J. Biol. Chem. 2004; 279:2906029065. [PubMed: 15123632]

42. Ridley AJ, Hall A. The small GTP-binding protein rho regulates the assembly of focal adhesions and actin stress fibers in response to growth factors. Cell. 1992; 70:389-399. [PubMed: 1643657]

43. Ren X-D, Kiosses WB, Sieg DJ, Otey CA, Schlaepfer DD, Schwartz MA. Focal adhesion kinase suppresses Rho activity to promote focal adhesion turnover. J. Cell Sci. 2000; 113:3673-3678. [PubMed: 11017882] 
44. Amano M, Ito M, Kimura K, Fukata Y, Chihara K, Nakano T, Matsuura Y, Kaibuchi K. Phosphorylation and activation of myosin by Rho-associated kinase (Rho-kinase). J. Biol. Chem. 1996; 271:20246-20249. [PubMed: 8702756]

45. Sandquist JC, Swenson KI, DeMali KA, Burridge K, Means AR. Rho kinase differentially regulates phosphorylation of nonmuscle myosin II isoforms A and B during cell rounding and migration. J. Biol. Chem. 2006; 281:35873-35883. [PubMed: 17020881]

46. Siemann DW. The unique characteristics of tumor vasculature and preclinical evidence for its selective disruption by Tumor-Vascular Disrupting Agents. Cancer Treat. Rev. 2011; 37:63-74. [PubMed: 20570444]

47. Zhou H, Hallac RR, Lopez R, Denney R, MacDonough MT, Li L, Liu L, Graves EE, Trawick ML, Pinney KG, Mason RP. Evaluation of tumor ischemia in response to an indole-based vascular disrupting agent using BLI and 19F MRI. Am. J. Nucl. Med. Mol. Imaging. 2015; 5:143-153. [PubMed: 25973335] 


\section{Highlights}

- The indole-based OXi8006 and its phosphate prodrug OXi8007 are potent vascular disrupting agents.

- Bioluminescence imaging in a breast cancer xenograft mouse model demonstrated that OXi8007 is a potent VDA in vivo.

- VDA properties were confirmed by complementary studies in activated endothelial cells.

- OXi8006 treatment resulted in microtubule disruption, and activation of RhoA kinase.

- Phosphorylation of focal adhesion kinase is essential for the OXi8006 mechanism. 

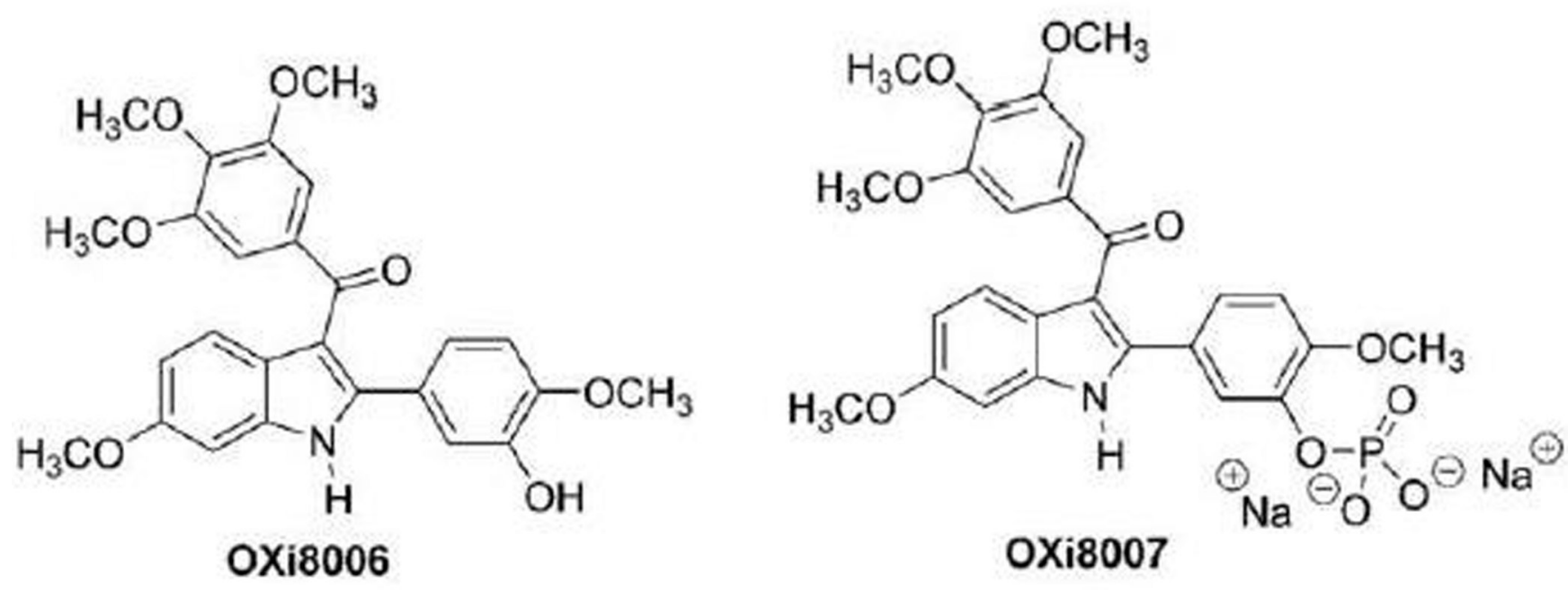

Figure 1.

Small-molecule inhibitors of tubulin assembly. OXi8006 and its phosphate prodrug OXi8007. 


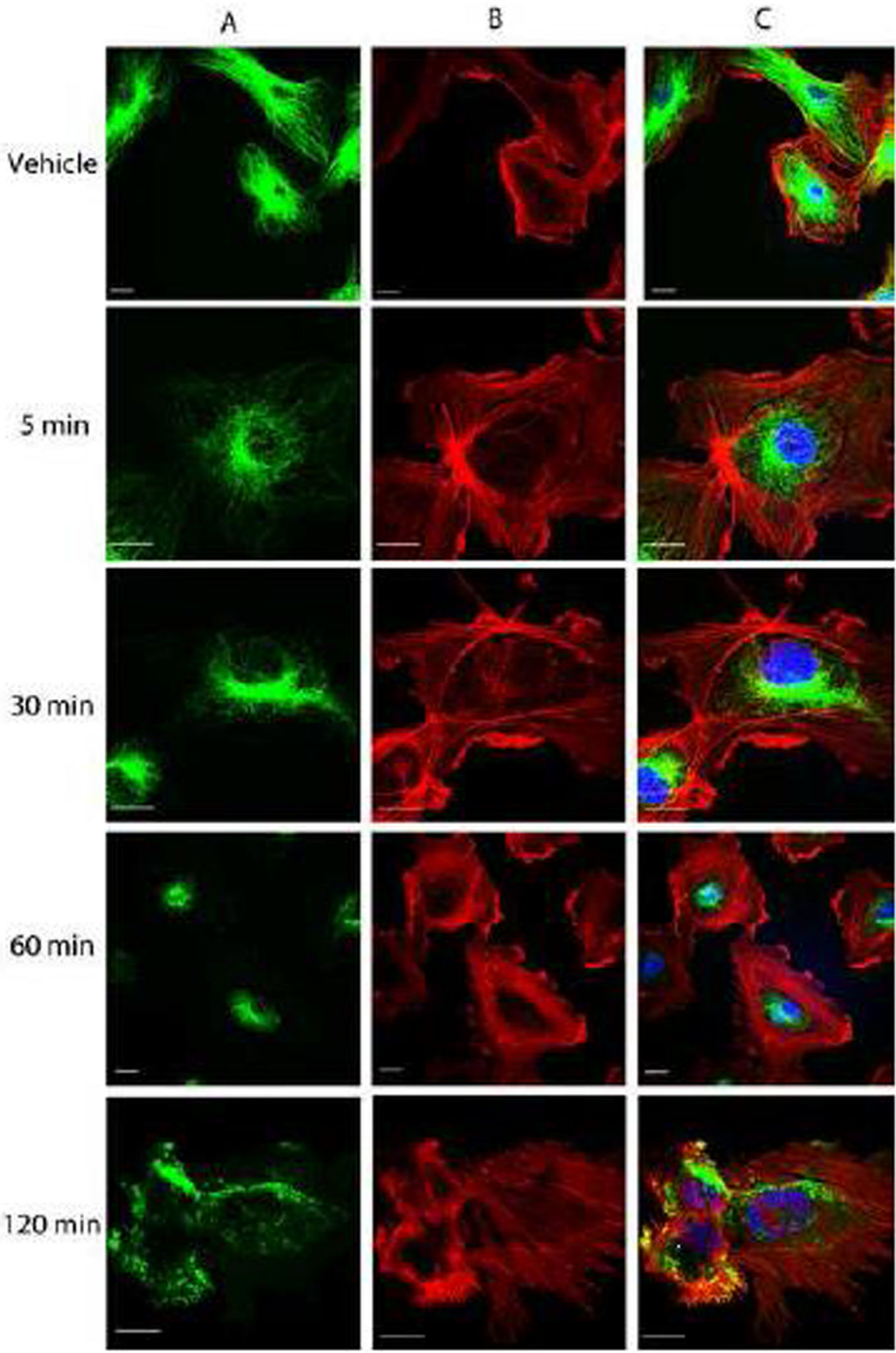

Figure 2.

Representative confocal images of the morphological effects of OXi8006 treatment on activated HUVECs. Monolayers of rapidly growing HUVECs on gelatin coated glass coverslips were treated with vehicle or $10 \mathrm{nM}$ OXi8006 for the indicated times $(5,30,60$ and $120 \mathrm{~min}$ ). Endothelial cells were fixed and stained with (A) anti-a-tubulin antibody (green, microtubules), (B) Texas red conjugated phalloidin (red,actin) and (C) DAPI (blue, nuclei), merged image. Bars, $20 \mu \mathrm{m}$. (For interpretation of the references to color in this figure legend, the reader is referred to the web version of this article.) 
A

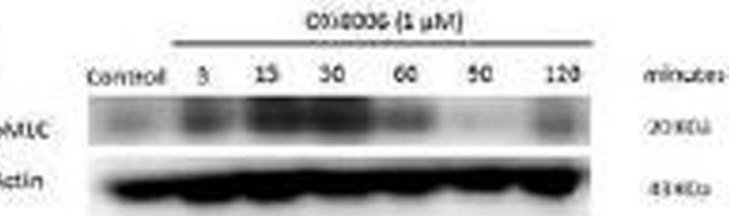

$\mathrm{B}$

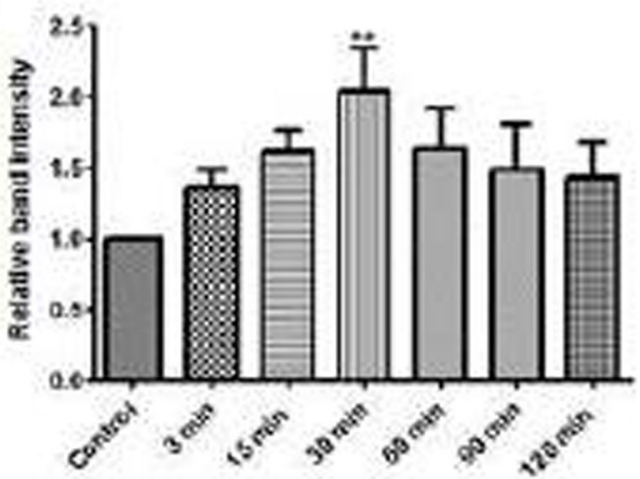

C

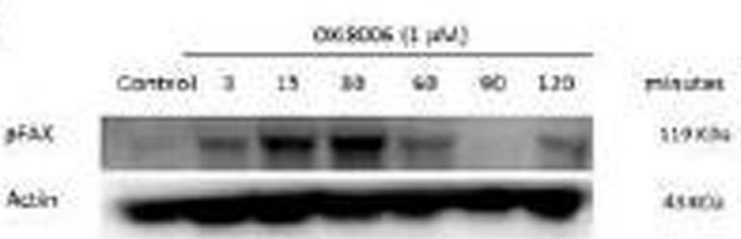

$\mathrm{D}$

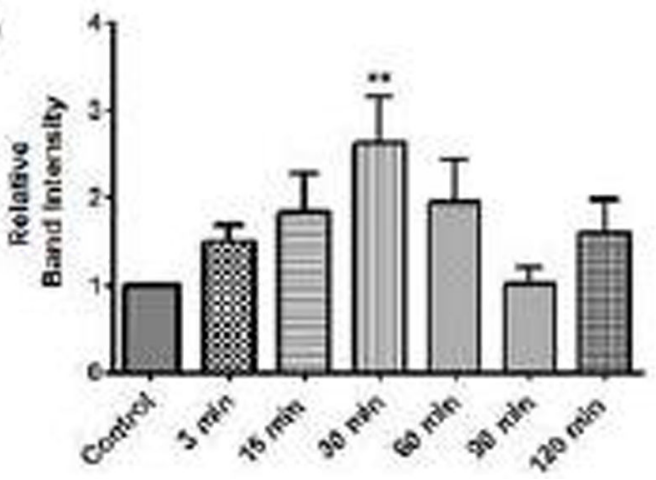

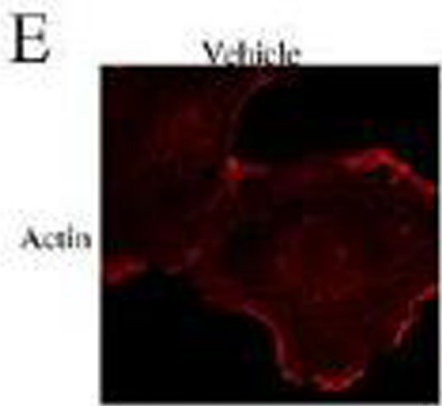
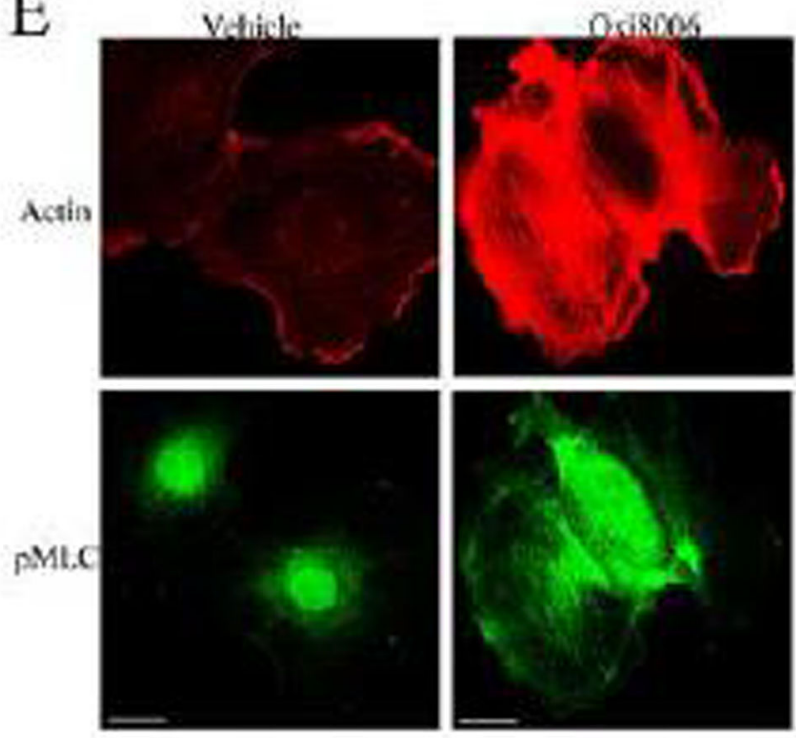

F
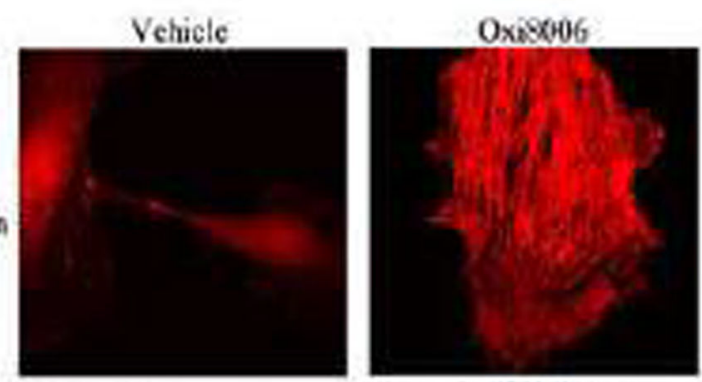

Figure 3.

OXi8006 treatment of activated endothelial cells results in increased MLC and FAK phosphorylation. (A) Treatment $(1 \mu \mathrm{M})$ initiated increased MLC phosphorylation starting at 3 min, reaching a maximum at $30 \mathrm{~min}$ and then slowly decreasing. (B) Quantification of the optical density of the pMLC protein band $(18 \mathrm{kDa})$ normalized to that of the actin band from western blots of OXi8006-treated HUVEC lysates and untreated controls. (C) FAK phosphorylation (pY397) increased starting at $3 \mathrm{~min}$, reaching a maximum at $30 \mathrm{~min}$ and then slowly decreasing. (D) Quantification of the optical density of the pFAK protein band $(120 \mathrm{kDa})$ normalized to that of the actin band from western blots of OXi8006 treated HUVEC lysates and untreated controls. Data in bar graphs are presented as mean \pm S.E.M. $* * \mathrm{p}<0.01$. (E) Representative confocal images of cells treated with vehicle or $100 \mathrm{nM}$ OXi8006 for $2 \mathrm{~h}$ and stained with Texas red conjugated phalloidin (red/actin) and anti- 
pMLC antibody (green). (F) Representative confocal images of cells treated with vehicle or $100 \mathrm{nM}$ OXi8006 showing increased actin stress fiber accompanied by an increase in FAK phosphorylation (pY397). Focal adhesions and pFAK were localized to each end of actin stress fibers. Cells were fixed and stained with Texas red conjugated phalloidin (red, actin) and anti-FAK pY397 antibody (white, pFAK). (For interpretation of the references to color in this figure legend, the reader is referred to the web version of this article.) 

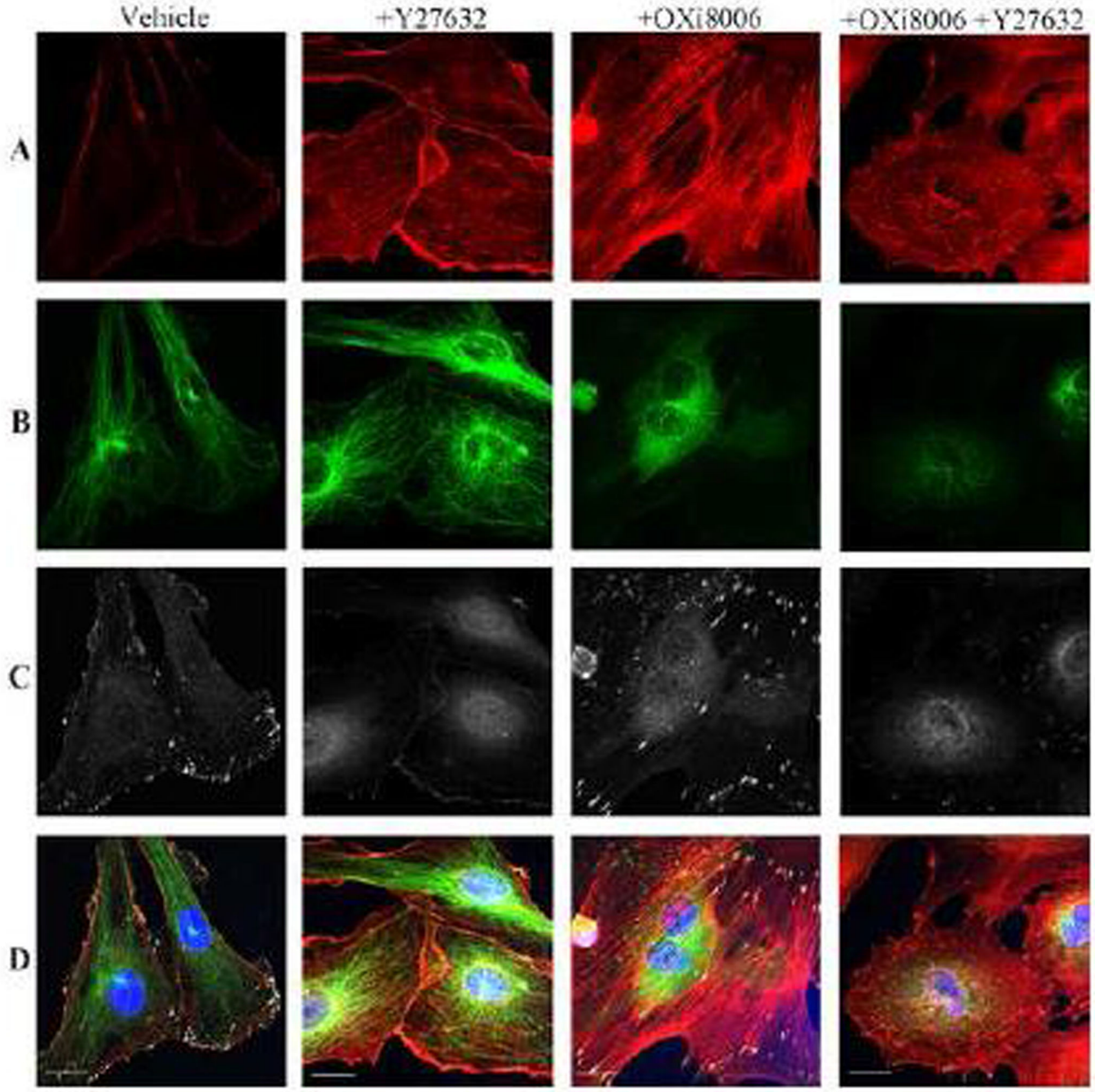

Figure 4.

OXi8006 induced increase in stress fiber formation and phosphorylation of FAK (pY397), but not microtubule disruption, is mediated by RhoA/RhoA kinase. Monolayers of rapidly growing HUVECs on gelatin-coated glass coverslips were treated with vehicle, pre-treated for 30 min with $10 \mu \mathrm{M}$ of the ROCK inhibitor Y-27632 (+Y-27632), $100 \mathrm{nM}$ OXi8006 for 2 $\mathrm{h}$ (+OXi8006), or pre-treated for $30 \mathrm{~min}$ with $10 \mu \mathrm{M}$ of the ROCK inhibitor Y-27632 and then treated with $100 \mathrm{nM}$ OXi8006 for $2 \mathrm{~h}(+\mathrm{Y}-27632,+$ OXi8006). Representative confocal images for endothelial cells fixed and stained with (A) Texas red conjugated phalloidin (red, 
actin), (B) anti-a-tubulin antibody (green, microtubules), (C) anti-FAK pY397 antibody (white, pFAK), and (D) DAPI (blue, nuclei), merged image. Bars, $20 \mu \mathrm{m}$. (For interpretation of the references to color in this figure legend, the reader is referred to the web version of this article.) 
A

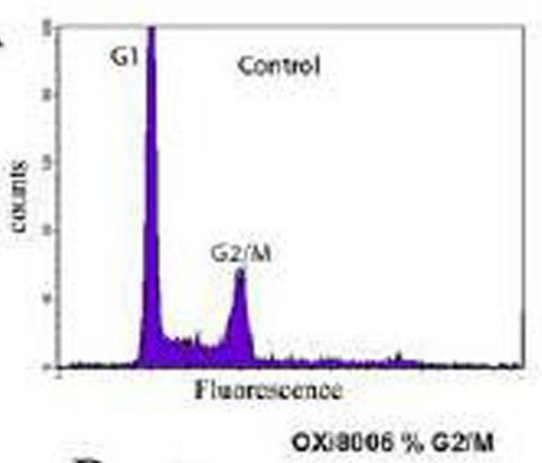

D

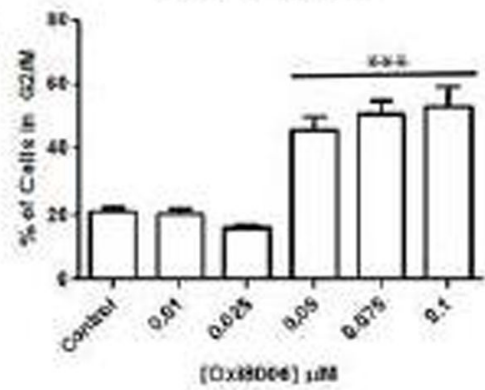

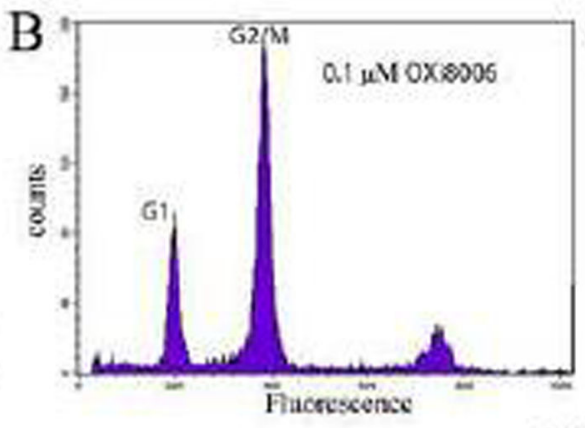

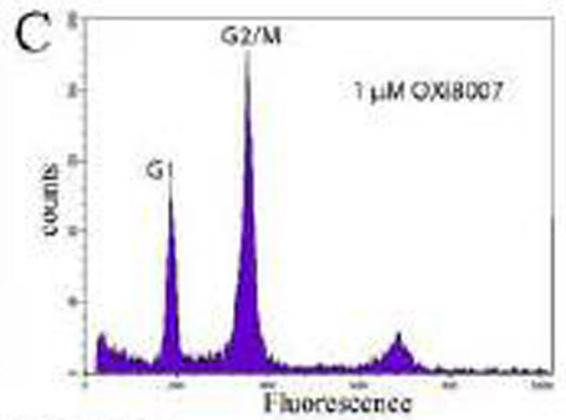

E
$0 \times 18007 \%$ G2M

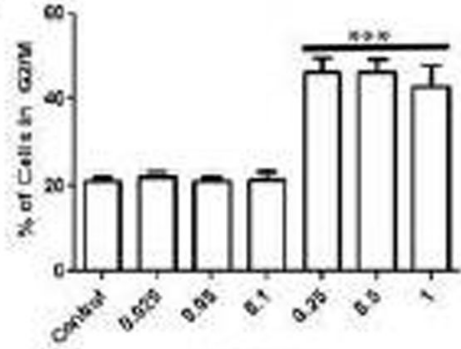

rOsisogh am

Figure 5.

OXi8006 and OXi8007 induced G2/M arrest in HUVECs. (A-C) Representative DNA histograms and $(\mathrm{D}, \mathrm{E})$ bar graphs show concentration dependent increase in the fraction of cells arrested at the G2/M phase upon OXi8006 and OXi8007 treatment. DNA content was assessed by flow cytometry. Data in bar graphs represent three independent experiments and are presented as mean \pm S.E.M. $* * * p<0.001$. 

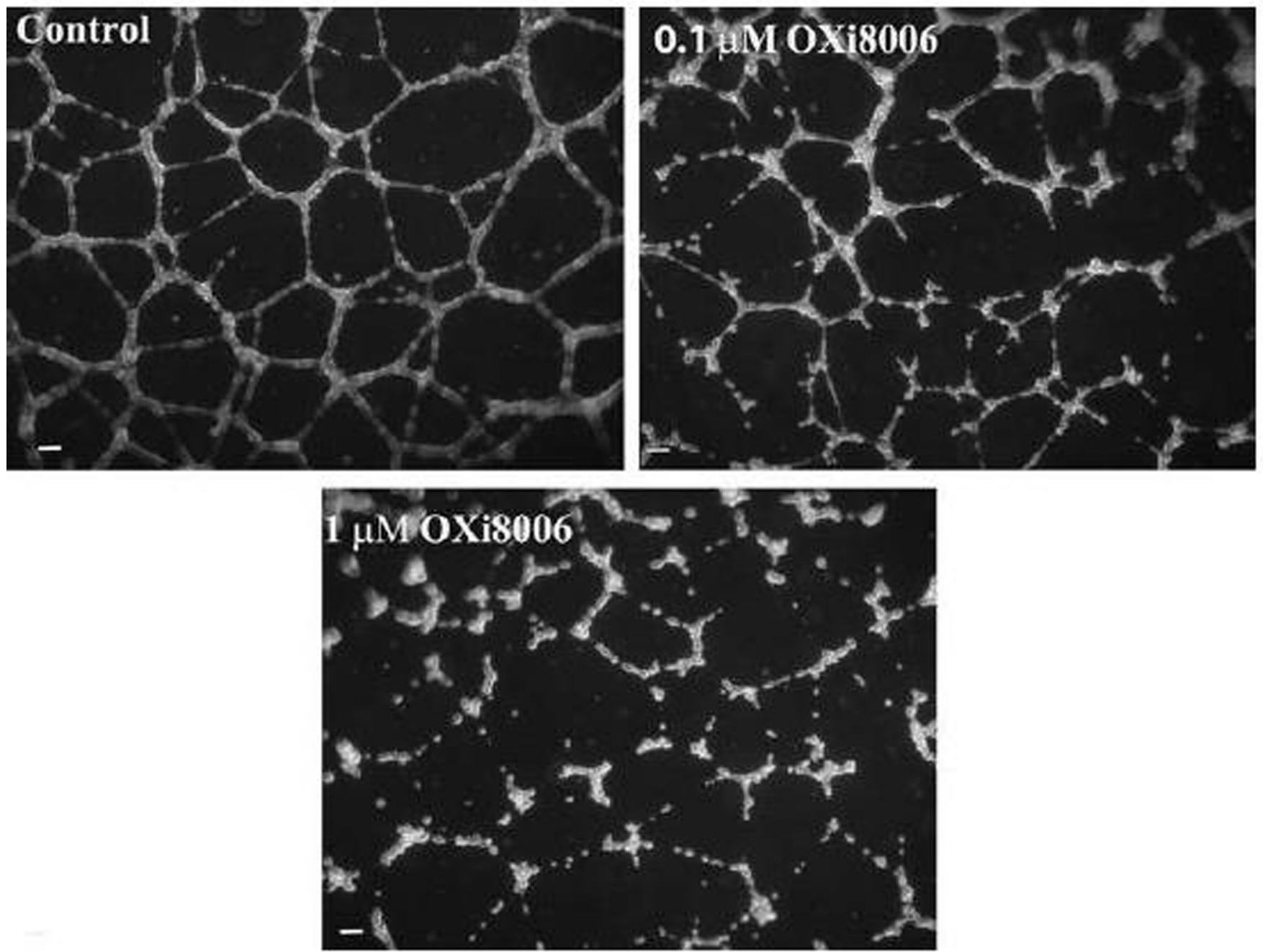

Figure 6.

OXi8006 treatment disrupts pre-established endothelial capillary-like networks. Treatment ( $2 \mathrm{~h}$ ) of pre-established endothelial capillary-like networks with OXi8006 showed a dose dependent increase in tube disruption $(0.1 \mu \mathrm{M}$, top right, $1 \mu \mathrm{M}$, bottom). Cells were imaged with an inverted microscope $(5 x)$ and nine fields were photographed per well. A minimum of three independent experiments were carried out for each treatment, and representative images are shown. Bars, $100 \mu \mathrm{m}$. 

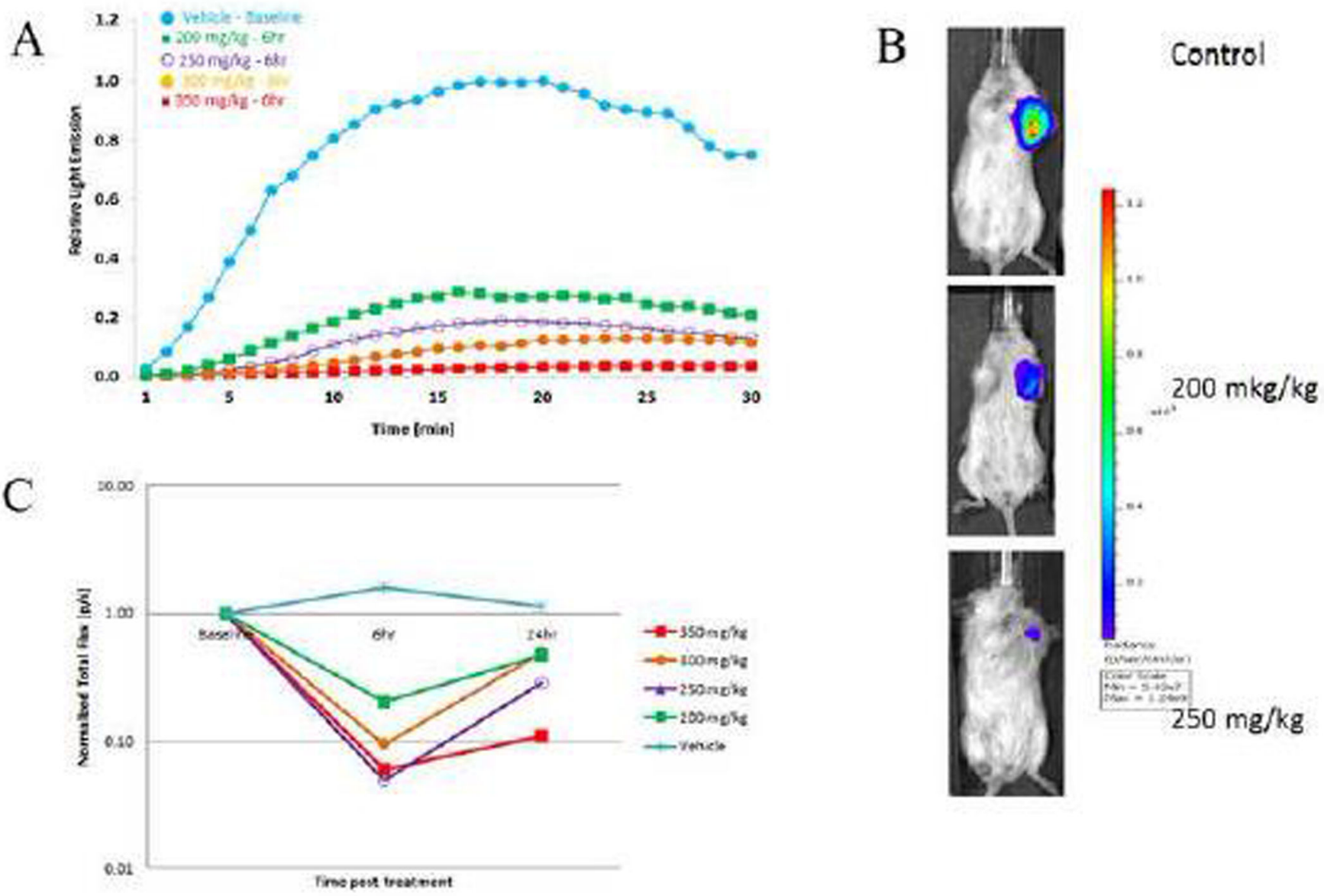

Figure 7.

Dynamic BLI assessment of dose escalation response to OXi8007. Increasing doses of OXi8007 were administered to SCID mice bearing luciferase expressing MDAMB-231-luc human breast cancer xenografts. Dynamic BLI was performed at baseline, and repeated $6 \mathrm{~h}$ and $24 \mathrm{~h}$ after OXi8007 with fresh luciferin administered SC $(120 \mathrm{mg} / \mathrm{kg})$ on each occasion. (A) Representative signal intensity curves for individual tumors showing increase of light emission over 15 minutes following administration of luciferin. Highest signal was seen for control tumor (blue) with lower signals for higher doses of OXi8007 (200 mg/kg green, 250 $\mathrm{mg} / \mathrm{kg}$ purple, $300 \mathrm{mg} / \mathrm{kg}$ orange, $350 \mathrm{mg} / \mathrm{kg}$ red). (B) Images for control, 200 and 250 $\mathrm{mg} / \mathrm{kg}$ showing maximum signal about $17 \mathrm{~min}$ after luciferin administration. (C) Normalized mean signal intensity for groups of tumors at each dose observed 17 minutes after luciferin was administered showing dose dependent vascular shutdown ( $\mathrm{n}=3$ tumors per group except $300 \mathrm{mg} / \mathrm{kg}$ where $\mathrm{n}=2$ ). (For interpretation of the references to color in this figure legend, the reader is referred to the web version of this article.) 
A

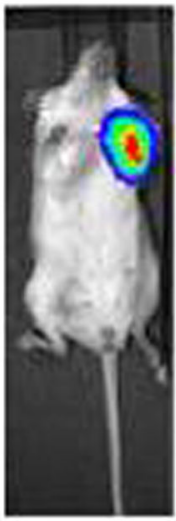

\section{c}

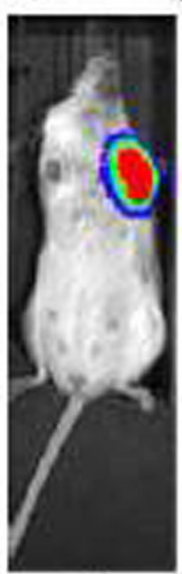

$\mathrm{Oh}$
OXi8007 $(350 \mathrm{mg} / \mathrm{kg})$

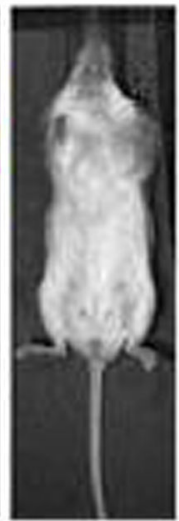

Saline Vehicle (control)

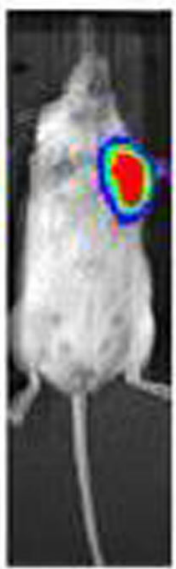

$2 \mathrm{~h}$
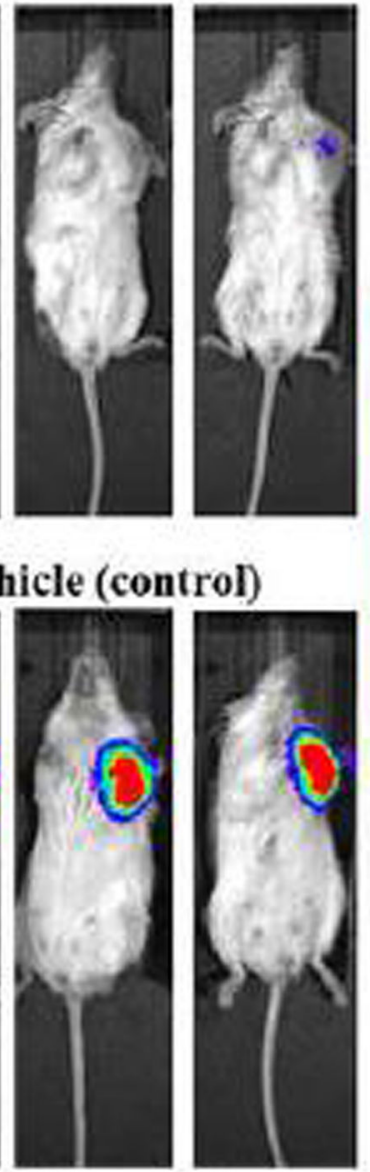

$6 \mathrm{~h}$

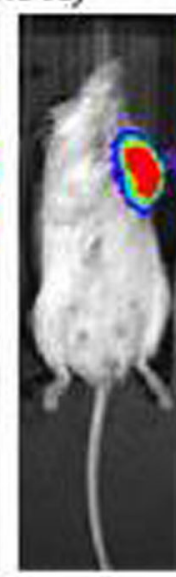

$24 \mathrm{~h}$
B

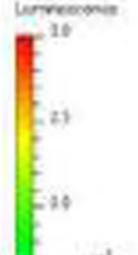

mat

\section{D}
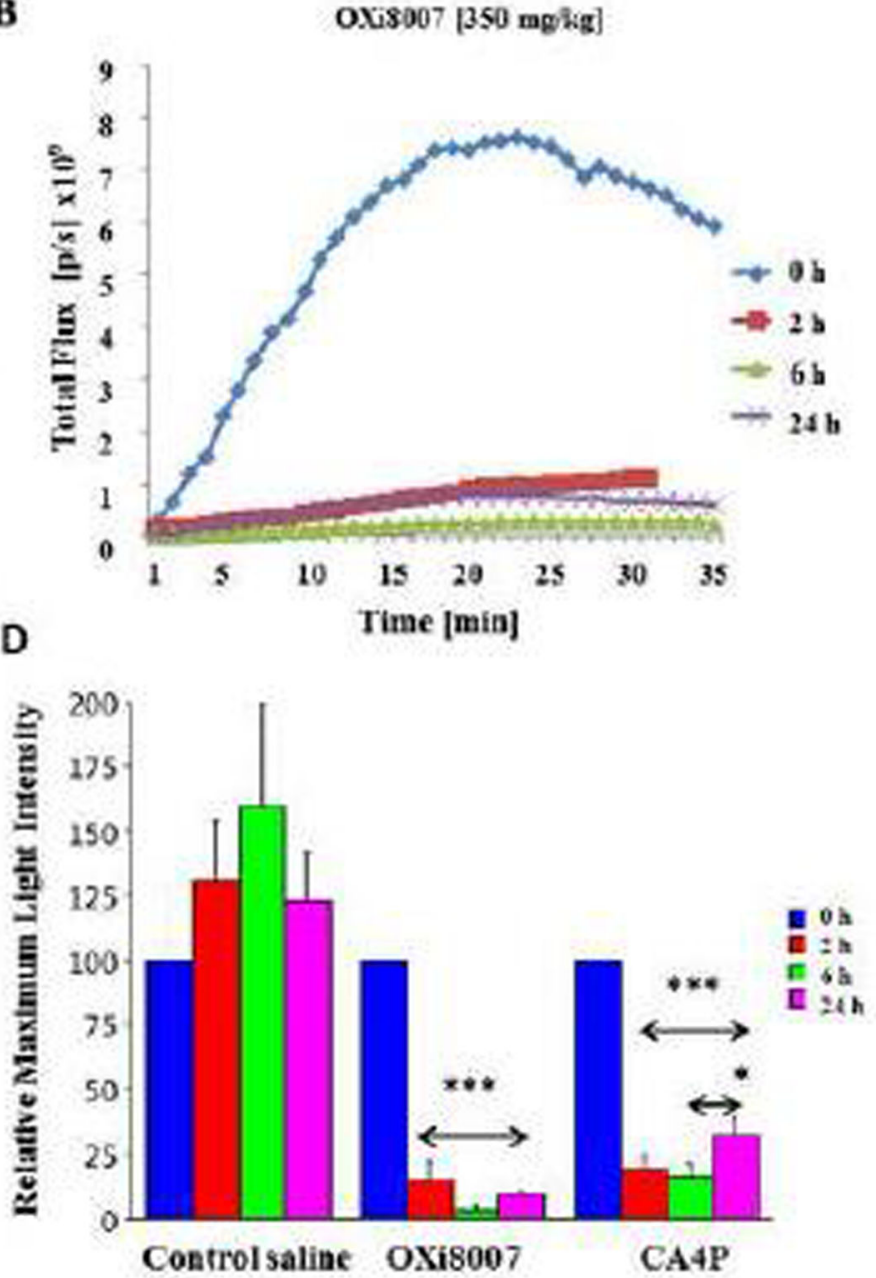

Figure 8.

MDA-MB-231-luc breast tumor response to OXi8007 treatment assessed by BLI. Sequential images of representative SCID mice bearing orthotopic MDA-MB-231-luc breast tumors growing in the mammary fat pad were obtained following administration of (A) OXi8007 (350 mg/kg) and (C) saline vehicle. Signals were obtained at 2, 6, and $24 \mathrm{~h}$ after treatment and 15 minutes after fresh luciferin substrate injection. (B) Representative dynamic BLI showing signal intensity evolution over 35 minutes for an MDA-MB-231-luc tumor from a mouse treated with OXi8007 (350 mg/kg). (D) Bar plot for normalized mean maximum BLI signal \pm S.D. of tumors from cohorts of mice $(n=5)$ at different time-points post drug administration. OXi8007 and CA4P induced significant reduction in BLI of tumors $(* * * \mathrm{p}<$ 0.001, *p < 0.05). OXi8007 BLI signal remained low at $24 \mathrm{~h}$ whereas CA4P showed significant recovery between 6 and 24 h post treatment $(* \mathrm{p}<0.05)$. 
A
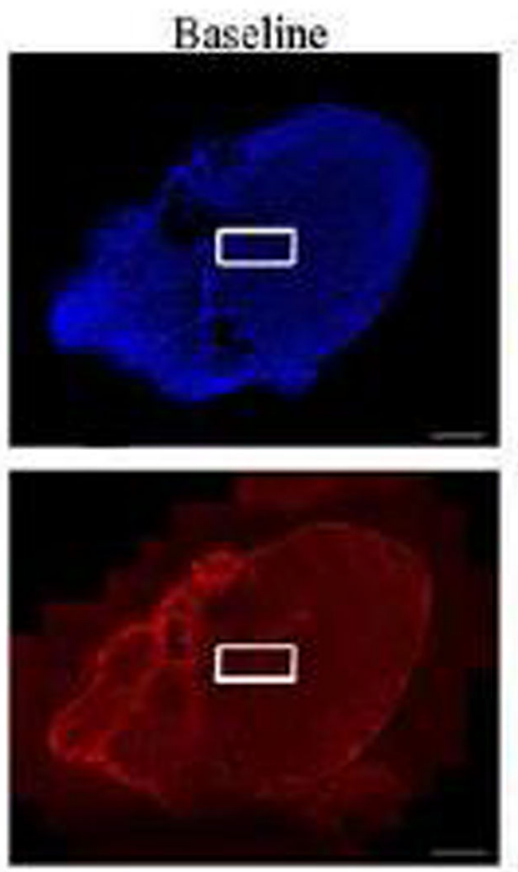

B

Figure 9.
Hoechst 33342

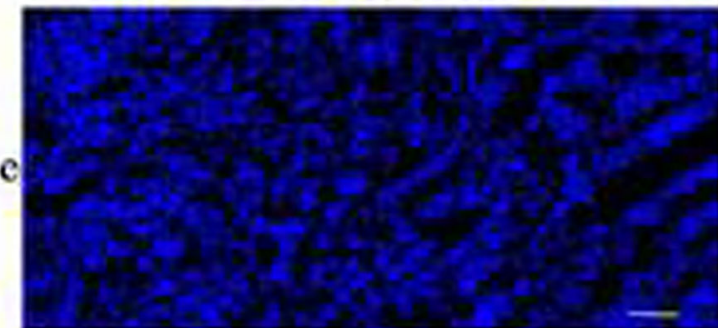

$6 \mathrm{~h}$
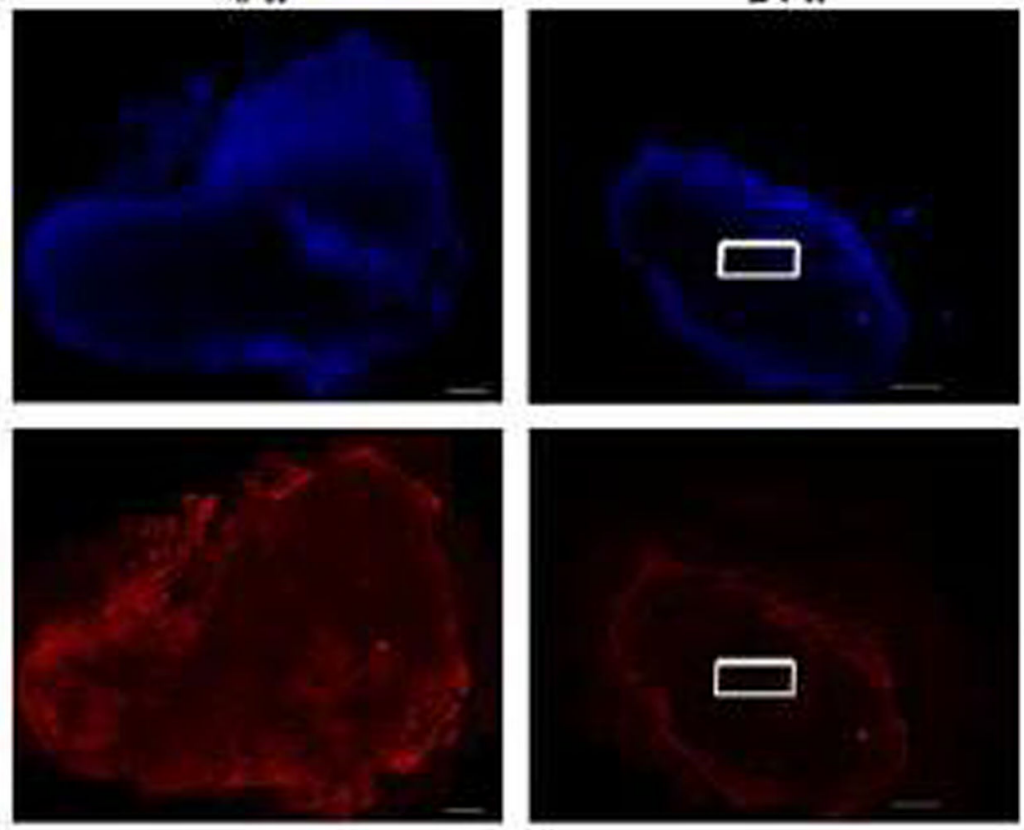

CD $31-$ Cy5

$24 \mathrm{~h}$

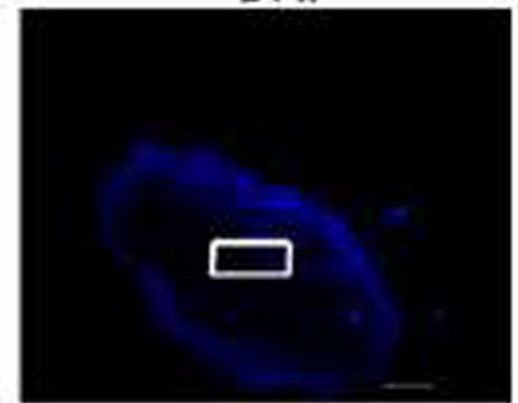

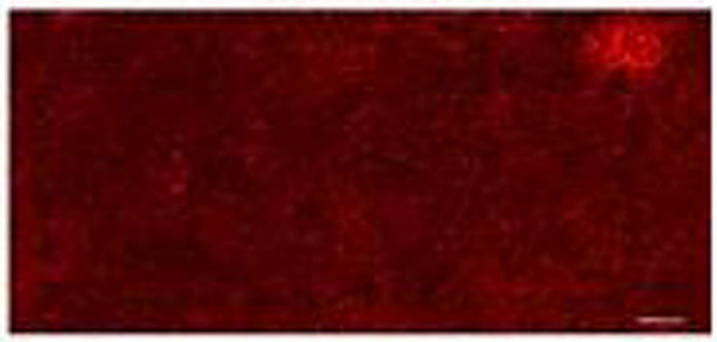

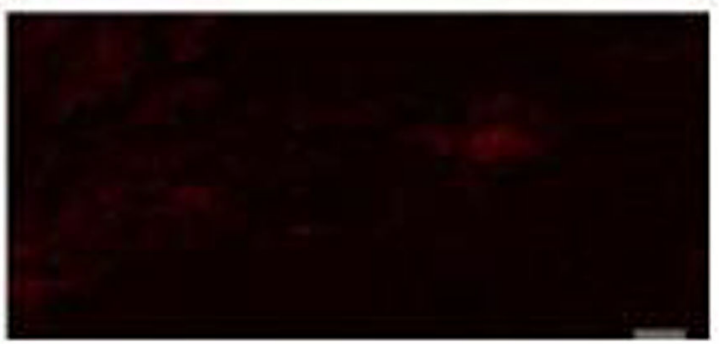

Histological evaluation of MDA-MB-231-luc tumor xenografts after OXi8007 administration confirmed vascular shutdown. (A) Hoechst 33342 dye was infused into mice (IV) 1 minute prior to sacrifice to selectively stain perfused regions. Tumor sections revealed tumor perfusion (top panel, blue) based on distribution of Hoechst 33342 and vascular structure based on Cy3-conjugated secondary antibody staining of CD31 (bottom panel, red) to show the presence of endothelial cells. There is general initial perfusion in vehicle treated mice, significant reduction of perfusion $6 \mathrm{~h}$ post administration, and only intense peripheral 
perfusion at $24 \mathrm{~h}$ post administration. The pattern of CD31 staining matches the perfusion seen with the Hoechst 33342 staining. Bars, $1000 \mu \mathrm{m}$. (B) 20x images of baseline and $24 \mathrm{~h}$ treated tumor sections stained with Hoechst 33342 dye and Cy3-conjugated secondary antibody for CD31. Images are taken from area corresponding to white rectangles in (A). Bars, $100 \mu \mathrm{m}$. (For interpretation of the references to color in this figure legend, the reader is referred to the web version of this article.) 


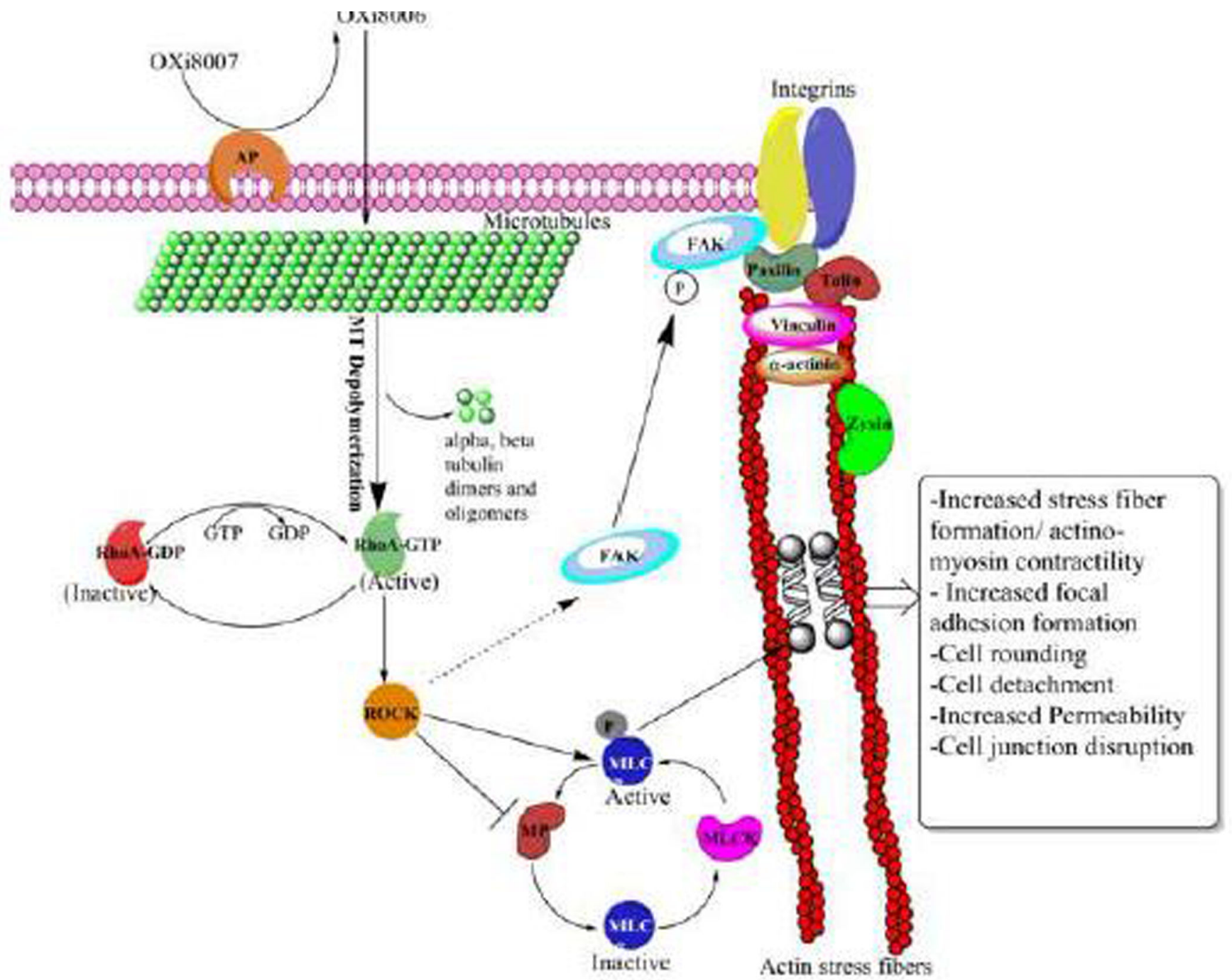

Figure 10.

Proposed VDA mechanism of action of OXi8007 in activated endothelial cells. Phosphate prodrug OXi8007 is cleaved by a non-specific phosphatase to OXi8006 that enters the endothelial cell and binds to tubulin resulting in microtubule depolymerization and RhoA activation. RhoA kinase (ROCK) is activated by RhoA and phosphorylates MLC and phosphorylates and inactivates MLC phosphatase (MP) leading to increased levels of phosphorylated MLC and activation of non-muscle myosin II which results in actin bundling and stress fiber formation. ROCK also leads to focal adhesion kinase (FAK) phosphorylation and activation contributing to increased focal adhesions. 


\section{Table 1}

OXi8006 and OXi8007 inhibited the growth of activated human umbilical vein endothelial cells (HUVECs) and human breast cancer cells (MDA-MB-231).

\begin{tabular}{lccc}
\hline & $\begin{array}{c}\text { Doxorubicin } \\
(\mathbf{n M})\end{array}$ & OXi8006 (nM) & OXi8007 (nM) \\
\hline HUVECs (activated) & $48.7 \pm 45.9$ & $33.4 \pm 1.13$ & $40.6 \pm 9.9$ \\
MDA-MB-231 & $116 \pm 101$ & $37.5 \pm 8.5$ & $31.9 \pm 11.6$ \\
\hline
\end{tabular}

Values were derived from SRB assay of a minimum of at least 3 independent experiments and are presented as averaged GI50 values \pm S.D. 